\title{
ÉXITO Y DIFUSIÓN DE LA LITERATURA DE PROBLEMAS EN LA CASTILLA DEL SIGLO XVI: LA TRADUCCIÓN CASTELLANA DE IL PERCHÉ DE GIROLAMO MANFREDI (ZARAGOZA, 1567)
}

\author{
Antònia Carré \\ Lluís Cifuentes
}

Universitat de Barcelona

\section{RESUMEN}

Descripción y análisis del Libro llamado el Porqué (1567), versión castellana de Pedro de Ribas del exitoso Liber de homine o Il Perché (1474), a la vez régimen de salud y tratado de fisiognomía, escrito por el médico boloñés Girolamo Manfredi (ca 1430-1493). Se estudia la difusión de esta obra de Manfredi (las numerosas ediciones italianas realizadas en los siglos XV, XVI y XVII, la traducción catalana anónima impresa en 1499 y las cinco reimpresiones de la traducción castellana llevadas a cabo durante el siglo XVI) en el contexto de la proliferación del género de los problemata en la Castilla del siglo XVI.

PALABRAS CLAVE: Medicina, regimina sanitatis, fisiognomía, problemata, traducciones, Italia, Castilla, Renacimiento.

\begin{abstract}
Description and analysis of the Libro llamado el Porqué (1567), the Castilian version by Pedro de Ribas of the successful Liber de homine or Il Perché (1474), a regimen of health and a treatise of physiognomy, written by the Bolognese physician Girolamo Manfredi (ca. 1430-1493). The diffusion of Manfredi's work (the numerous Italian editions made in the 15th, 16th and 17th centuries, the anonymous Catalan translation printed in 1499 and the five reprints of the Castilian translation carried out during the 16th century) is studied in the context of the proliferation of the problemata gender in 16th-century Castile.
\end{abstract}

KEY WORDS: Medicine, regimina sanitatis, physiognomy, problemata, translations, Italy, Castile, Renaissance. 
El género de las cuestiones naturales, de historia ininterrumpida desde el siglo XII hasta el XVII, había sido muy utilizado en la literatura médica presalernitana y en las cuestiones salernitanas ${ }^{1}$ a partir de los Problemata pseudo-aristotélicos ${ }^{2}$ y sus derivados, que fueron redescubiertos hacia el año 1300. En los siglos XV y XVI, este antiguo género vivió tiempos de nueva popularidad con la confección de distintas colecciones de problemas que alcanzaron una gran difusión con la imprenta.

Los problemas, definidos ya por Aristóteles como un ejercicio para el entrenamiento dialéctico ${ }^{3}$, son usados en cuestiones causales (responden, pues, a la pregunta por qué? $)^{4}$ referidas a fenómenos conocidos y, por lo tanto, no

1 El esquema de pregunta concisa y respuesta (quaestiones et responsiones), con pocos trazos de disputación, era la forma de aprendizaje utilizada en las escuelas que, desde Salerno, se extendió por toda la Europa latina occidental al convertirse en la base de las disputaciones escolásticas sobre physica. Sobre el género de la quaestio en textos de filosofía natural, véase LAwn, B. (1963), The Salernitan Questions: An Introduction to the History of Medieval and Renaissance Problem Literature, Oxford, Clarendon Press [trad. it. ampliada y corregida (1969): I quesiti salernitani: Introduzione alla storia della letteratura problematica medica e scientifica nel Medioevo e nel Rinascimento, Nápoles, Di Mauro]; LAWN, B. (1979), ed., The Prose Salernitan Questions, Londres-Oxford, Oxford University Press for the British Academy; Lawn, B. (1993), The Rise and Decline of the Shcolastic Quaestio Disputata, with Special Emphasis on its Use in the Teaching of Medicine and Science, Leiden, Brill.

2 Los Problemata Aristotelis constituyen un conjunto de textos elaborados en la escuela peripatética hasta el siglo V o VI dC, que tuvieron imitadores en Sorano, Casio el atropista y el pseudo-Alejandro de Afrodisia. Véase Forster, E.S. (1928), «The Pseudo-Aristotelian Problems, Their Nature and Composition», Classical Quarterly, 163-165; BLAIR, A. (1999a), «The 'Problemata' as a Natural Philosophical Genre», en GrAfTON, A., y SiRAISI, N.G., eds., Natural Particulars: Nature and the Disciplines in Renaissance Europe, Cambridge, MTI Press, 171-204; BLAIR, A. (1999b), «Authorship in the Popular Problemata Aristotelis», Early Science and Medicine, 4(3), 189-227; LAWN (1963), cap. 7. Véase también D'ALVERNY, M.Th. (1976), «La tradition manuscrite des Questiones Nicolai peripatetici», en ALEXANDER, J.J.G., y GiBson, M.T., eds., Medieval Learning and Literature: Essays Presented to Richard William Hunt, Oxford, Clarendon Press, 200-219.

En el siglo XVI, al parecer de la mano del valenciano Joan Lluís Vives, se pone definitivamente en duda la autoría del Filósofo sobre este texto. Véase al respecto MONFASANI, J., «The Pseudo-Aristotelian Problemata and Aristotle's De Animalibus in the Renaissance», en GRAFTON y SIRAISI (1999), 205-247, p. 213; y, sobre el pseudo-Aristóteles en general, KRAYE, J., et al., ed. (1986), Pseudo-Aristotle in the Middle Ages: The 'Theology' and Other Texts, Londres, Warburg Institute.

3 Así lo dice en los Topica, 1.11. Blair, A. (1999a), p. 175.

4 Es evidente que detrás de ello existe el concepto aristotélico que entiende el conocimiento filosófico como un conocimiento causal. 
tienen la intención de producir conocimiento nuevo, sino que pretenden ordenar lo que ya se conoce y relacionarlo con las observaciones y la experiencia cotidianas. Por ello, el método de pregunta y respuesta traspasó los propósitos didácticos de las aulas universitarias ${ }^{5}$ (donde había sido usado -en latín, por supuesto- con notable repercusión en temas de filosofía natural y physica por maestros como Pedro Hispano —-después papa bajo el nombre de Juan XXIo Alberto Magno) ${ }^{6}$ y se utilizó en obras que habrían de proporcionar una formación básica sobre las ideas científicas a personas de condiciones diversas.

Evidentemente, el género de los problemas no fue el único utilizado en la divulgación científica: la compleja tradición del Secretum secretorum pseudoaristotélico, con sus ramificaciones y derivaciones en libros de secretos de las más variadas materias, que en ocasiones se sirvieron también de la metodología de las cuestiones, o la rica producción de obras dialogadas, que no tendremos en cuenta aquí, realizaron idéntica función? ${ }^{7}$.

Aunque en los siglos XV y XVI se escribieron libros de problemas en latín en distintos países de la Europa occidental, también se compusieron colecciones de problemas en distintas lenguas vernáculas ${ }^{8}$. Estas colecciones, destina-

5 Sobre la lectio, la quaestio y la disputatio, métodos didácticos que se implantaron progresivamente en todas las universidades escolásticas a partir de su uso en las facultades de teología, véase BAZÀn, B.C., WiPPEL, J.W., FrANSEN, G., y JACQUART, D. (1985), Les questions disputées et les questions quodlibétiques dans les facultés de Théologie, de Droit et de Médecine, Turnhout, Brepols (Typologie des Sources du Moyen Age Occidental, 44-45).

6 LAWN (1963), pp. XII, 76-78 y 85.

7 Sobre el Secretum secretorum véase GRIGNASCHI, M. (1980), «La diffusion du Secretum Secretorum (Sirr al-Asrār) dans l'Europe occidental», Archives d'historie doctrinale et littéraire du Moyen Âge, 55, 7-70; RYAn, W.F., y SchmitT, Ch.B., eds. (1982), PseudoAristotle the Secret of Secrets. Sources and Influences, Londres, The Warburg Institute (Warburg Institute Surveys, IX); ZAMUNER, I. (2005), «La tradizione romanza del Secretum secretorum pseudo-aristotelico», Studi Medievali, $3^{\mathrm{a}}$ serie, 46, 31-116. Sobre las obras dialogadas, véase, por ejemplo, Thomasset, C., ed. (1980), Placides et Timéo ou li secrés as philosophes, París-Ginebra, Librairie Droz; ThOMAsset, C. (1982), Commentaire du Dialogue de Placides et Timéo, Ginebra, Librairie Droz; RoncA, I. (1997), Guillelmi de Conchis Dragmaticon philosophiae, cura et sudio -, Summa de Philosophia in vulgari, cura et studio L. BADIA [et] J. Pujol, Tournhout, Brepols (Corpus Christianorum, Continuatio Medievalis, CLII); las obras de Francisco López de Villalobos (véase la nota 47); o las de Pedro Mercado (Diálogos de Philosophia Natural y Moral, Granada, 1558).

8 Documentamos autores de problemas latinos en Portugal, Alemania, Francia e Inglaterra. En lengua vernácula, sabemos de dos obras escritas con anterioridad al siglo XV: el divulgadísimo Livre de Sidrach, anónimo francés de finales del siglo XIII, y L'acerba de Cecco d'Ascoli (muerto en 1327), escrita en italiano en terza rima. Véase al respecto LAWN (1963). 
das al entretenimiento y a la instrucción de los sectores extracadémicos, marcaron la extraordinaria difusión que la ciencia y la medicina alcanzaron entre esos sectores en los siglos XVI y XVII. Conocemos la existencia de libros de problemas en italiano, en castellano y en catalán.

Girolamo Manfredi, uno de los primeros autores de problemas de quien tenemos noticia, publicó en 1474 su colección de problemas -objetivo de estas páginas - que, tal como veremos, se tradujo desde el italiano original a dos de las lenguas ibéricas, el catalán (1499) y el castellano (1567). Los contactos de todo tipo entre ambas penínsulas mediterráneas, con el intermediario que, al menos hasta finales del siglo XV, fue la Corona de Aragón, se intensificaron durante los primeros siglos de la Edad Moderna como consecuencia del papel ejercido por la monarquía hispánica en el panorama internacional ${ }^{9}$.

Algunos de los autores de libros de problemas castellanos, al margen de los modelos latinos y posiblemente siguiendo las clasificaciones del saber promovidas por los studia humanitatis, que apareaban la filosofía natural y la filosofía moral ${ }^{10}$, dividen sus obras en dos grandes bloques: los problemas naturales, por un lado, y los morales, por otro. Así disponen sus obras, publicadas en 1543 y 1575 respectivamente, López de Villalobos y Jerónimo Campos, disposición que encontramos también en otros autores italianos del género, como Girolamo Garimberto (1549) ${ }^{11}$, Ortensio Lando (1550) ${ }^{12}$ y Bartolomeo Paschetti (1581) $)^{13}$ y que comparece todavía en la colección de Andrés Ferrer de Valcedebro impresa en Madrid en 1762. Esta semejanza clasi-

9 Sobre las relaciones culturales entre los estados de Italia y los reinos de la península Ibérica, véase Gómez Moreno, A. (1994), España y la Italia de los humanistas, Madrid, Gredos.

10 Véase JACOBS, H.C. (2002), Divisiones philosophiae: clasificaciones españolas de las artes y las ciencias en la Edad Media y el Siglo de Oro, Madrid, Iberoamericana, esp. el cap. 3.

11 Fue autor de unos Problemi naturali e morali, impresos en Venecia en 1549 y traducidos al francés en 1559. LAWN (1963), p. 138.

12 Lando escribió en latín las Miscellaneae questiones, impresas en Venecia en 1550, que luego tradujo al italiano con el título de Quattro libri de dubbi con le solutioni a ciascun dubbio accommodate: la materia del primo e naturale, del secondo e mista (benche per lo piu sia morale) del terzo e amorosa, \& del quarto e religiosa, obra impresa en Venecia en 1552. La versión italiana se imprimió en tres ocasiones en el siglo XVI (Venecia, 1555 y 1556; Piacenza, 1597) y se tradujo al francés (1558) y al inglés (1566, 1596, 1640); véase LAWN (1963), pp. 101 y 139. Sobre el autor, véase MelzI, G. (1848-1859+supl.), Dizionario di opere anonime e pseudonime di scrittori italiani o come che sia aventi relazione all'Italia, 3 vols., Milán, L. Di Giacomo Pirola [reimpr. en 4 vols. (1982), Sala Bolognese, A. Forni], vol. 2, p. 391.

13 En sus Dubbi morali et naturali (Génova, 1581), Bartolomeo Paschetti imita la obra anterior de Ortensio Lando, una prueba más de su enorme éxito. LAWN (1963), pp. 101 y 140. 
ficatoria podría ser fruto de la comunidad de intereses entre intelectuales de Castilla e Italia, que habían establecido contactos frecuentes a partir de su vinculación a los studia humanitatis. Efectivamente, los libros de problemas escritos en Italia eran conocidos en Castilla y viceversa: Jerónimo Campos trabajó directamente a partir de la obra de Ortensio Lando; Alonso de Fuentes fue traducido al italiano por Alfonso de Ulloa, que tradujo también la Philosofia natural de Juan de Jarava; y Alonso de Fuentes convirtió en protagonistas de su Summa de philosophia natural a un sevillano que pregunta y a un italiano que responde, distribución de papeles muy probablemente indicativa del área que era reconocida como promotora del género.

\section{LA LITERATURA DE PROBLEMAS EN CASTILLA}

La producción de literatura médica en la Corona de Castilla durante la baja Edad Media ha sido analizada por Luis García Ballester. ${ }^{14}$ Una de las características más relevantes que se desprenden de este estudio es la poca presencia de literatura médica autóctona anterior al siglo $\mathrm{XV}$, hecho justificable por la debilidad de las universidades ibéricas, como ya apuntó en su momento Guy Beaujouan ${ }^{15}$. En ese contexto hay que situar también las colecciones de problemas $^{16}$, que no aparecen en Castilla hasta el siglo XVI, aunque lo hacen con gran éxito, como lo atestiguan las distintas impresiones realizadas de una misma obra ${ }^{17}$. El modelo se toma, sin ninguna duda, de las traducciones lati-

14 García BALleSter, L. (2001), La búsqueda de la salud: sanadores y enfermos en la España medieval, Barcelona, Península.

15 Beaujouan, G. (1967), La science en Espagne aux XIVe et XVe siècles, París, Les Conférences du Palais de la Découverte, série D, num. 116, 5-45 [reimpr. en BEAujouAn, G. (1992), Science médiévale d'Espagne et d'alentour, Aldershot, Variorum (Collected Studies Series, 374), I].

16 LAWN (1963), esp. en el cap. 9, pp. 129-140, analiza a fondo la confección de colecciones de problemas, en latín y en lengua vernácula (castellano e italiano), entre los siglos XIII y XVII.

17 Las colecciones castellanas de problemas son estudiadas por CUARTERO SANCHO, P. (1990), «Las colecciones de problemas en el Siglo de Oro», Bulletin Hispanique, 92, 213-235, que desconoce los trabajos de Brian Lawn así como la traducción castellana de la obra de Girolamo Manfredi objeto de estas notas; SAnZ HermidA, J. (1993), «El género de preguntas y respuestas como popularización de la filosofía natural: la obra de A. López de Corella», Criticón, 58, 185-195; SANZ HERMIDA, J. (1997), Literatura de problemas en la España de los siglos XVI y XVII: Alonso López de Corella y Alonso de Fuentes, tesis doctoral de la Universidad de Salamanca, 1997 (cuya consulta no ha sido posible). 
nas de los Problemata pseudoaristotélicos que difundió la imprenta, ${ }^{18}$ pero también de las ediciones en italiano de las obras del género. Hay que señalar que las colecciones castellanas de problemas se caracterizan por el uso del verso, procedimiento utilizado con toda naturalidad en los medios académicos por sus virtudes nemotécnicas ${ }^{19}$. Recordemos tan sólo los poemas introductorios que el profesor de medicina de la Universidad de París, Jacques Despars $^{20}$, antepuso a sus comentarios al Canon de Avicena, que concluyó en 1453 y que se difundieron ampliamente en la Universidad de Salamanca, en cuyas aulas circularon sin ninguna duda los comentarios de Pietro d'Abano a los Problemata ${ }^{21}$. El mismo Francisco López de Villalobos, médico licenciado en Salamanca de quien trataremos más adelante, resumió en verso y en castellano el Canon, considerado entonces el mejor compendio de todo lo que un médico bien informado debía saber, en su Sumario de la medicina $(1498)^{22}$. La única obra estrictamente de cirugía que conocemos escrita en castellano es la Çirugia rimada del médico y cirujano Diego el Covo (o Cobos), concluida en 1412 aunque conservada sólo fragmentariamente en una

18 La traducción más antigua de los Problemata Aristotelis es la de Bartolomé de Messina, realizada entre 1258 y 1266 , que se difundió acompañada del comentario de Pietro d'Abano (1310). La traducción que tuvo más éxito con la imprenta fue la de Teodoro Gaza (1454), aunque no hay que olvidar que en muchas ediciones la traducción de Gaza se presentaba unida a la de Messina y por tanto al comentario de Pietro d'Abano. Tratamos más ampliamente este tema en CARRÉ, A., y CifuENTES, Ll. (en prensa), «Girolano Manfredi's Liber de homine (Il Perché)» In Italian and Iberian contexts: an example of the $15^{\text {th }}$ an $16^{\text {th }}$ century difussion of medical text in vernacular languages.

19 No hay que olvidar que la forma versificada - propia de un momento de transición entre la oralidad y la escritura- ya fue utilizada en algunos de los textos médicos de la llamada Escuela de Salerno. Véase al respecto Kristeller, P.O. (1986), Studi sulla Scuola medica salernitana, Nápoles, Istituto italiano per gli studi filosofici.

20 Sobre el célebre autor parisino, véase JACQUART, D. (1990), La médecine médiévale dans le cadre parisien: XIVè -XVè siècles, París, Fayard, p. 498; y JACQUART, D. (1980), «Le regard d'un médecin sur son temps: Jacques Despars (1380?-1458)», Bibliothèque de l'École des Chartes, 138, 35-86.

21 Salamanca vivió en el siglo XV el «renacer» de la escolástica médica que se difundió por la Europa occidental a finales del XIII y principios del XIV con el estudio de las obras de los médicos que marcaron las pautas intelectuales en esos siglos, como Arnau de Vilanova, Bernardo de Gordon, Taddeo Alderotti y Pietro d'Abano (Conciliator y los comentarios a los Problemata). Véase al respecto GARCía BALleSter (2001), en esp. el cap. 3 y p. 243.

22 SÁnchez Granjel, L., et al., eds. (1998), Francisco López de Villalobos, Sumario de la medicina (1498), Salamanca, Universidad de Salamanca-Real Academia de Medicina de Salamanca. 
copia de 1493, lo que indica la validez de la forma versificada en la literatura médica aún a finales del siglo $\mathrm{XV}^{23}$.

En las colecciones de problemas castellanas la pregunta suele ser en ver$\mathrm{so}^{24}$ y la respuesta puede aparecer en verso o en una glosa en prosa, o en una combinación de verso y prosa, sin duda por influjo de las poesías de preguntas y respuestas de los cancioneros, particularmente de las composiciones de perqué25.

El género aparece perfectamente definido por los compiladores castellanos. Como veremos a continuación, Hernán López de Yanguas, por ejemplo, afirma que problemas «quiere decir preguntas con sus respuestas». Así mismo, los autores no ocultan las fuentes utilizadas, que, por lo que aquí interesa, son Aristóteles, Plutarco, Alejandro de Afrodisia y, en algún caso, autores italianos del género.

Juan de Jarava, autor de un libro de problemas de los más interesantes, escrito únicamente en prosa, explica claramente por qué ha optado por el género en cuestión: por su didactismo, puesto que los temas a los que él se refiere (el amor y las cosas naturales) «son mejor entendidas quando a manera de pregunta se proponen y con mayor voluntad son leydas quando como un razonamiento de dos que hablan juntos preguntándose uno al otro son tratadas» ${ }^{26}$. $\mathrm{Y}$ es que los libros de problemas son textos más populares que técnicos, que introdujeron en España muchas de las teorías científicas que se debatían por entonces en Europa en un lenguaje apto para un público medianamente culto. «Sus autores castellanos son médicos, físicos, moralistas y escritores en gene-

23 Se ha conservado sólo el Tratado de las apostemas. Véase GARCíA BALLESTER (2001), pp. 398-400.

24 Respecto al verso de las colecciones de problemas castellanos, LAWN (1963), p. 135, apunta la influencia en ello de la tensó provençal, una contentio entre dos trovadores; véase también RIQUER, M. de (1975), Los trovadores: historia literaria y textos, Barcelona, Planeta, vol. 1, p. 67.

25 Sobre la caracterización del subgénero cancioneril de preguntas y respuestas, véase Chas Aguión, A. (1997), «Pues no es yerro preguntar...: notas para la revalorización de una modalidad poética cuatrocentista olvidada, las preguntas y respuestas», en BERESFORD, A.M., y Deyermond, A.D., eds., [Hispanic Studies:] Proceedings of the Eighth Colloquium, 1996, Queen Mary and Westfield College, Londres, Queen Mary and Westfield College-Department of Hispanic Studies, 85-93. Para un estudio de conjunto del tema preguntas y respuestas en la lírica del siglo XV, véase CHAS AGUIÓN, A. (2000), Amor y corte: la materia sentimental en las cuestiones poéticas del siglo $X V$, Noia, Toxosoutos.

26 Problemas o preguntas problemáticas, Alcalá de Henares, 1546, f. IIII (ejemplar en Madrid, BN, R 14294). 
ral de prestigio reconocido, lo que nos da razón de la importancia de este género ${ }^{27}$. Veamos ahora quienes son los autores de colecciones de problemas castellanas de los cuales tenemos notícia.

El primero de ellos es el médico navarro Alonso López de Corella ( $c a$. 1519-1584) ${ }^{28}$, que a su vez fue el creador de la incorporación del verso en el género de preguntas y respuestas. Estudió en Salamanca y Alcalá, donde posiblemente se licenció en medicina hacia 1542, y ejerció su profesión al servicio de la casa de Luna, luego en Peralta, en Corella y en el cabildo de Tarazona, villa que le vió morir. López de Corella, que nunca se casó ni tuvo hijos, fue un hombre de holgada posición económica, que vió aumentar su patrimonio gracias a su actividad profesional y a sus actuaciones como prestamista ${ }^{29}$. Tuvo tiempo también para la escritura de obras científicas, de las cuales ahora nos interesan sólo las que tienen relación con el género de los problemas. La primera de estas obras lleva por título Secretos de filosophía y medicina collegidos por el Bachiller Alonso López de Corella puestos a manera de perqué porque mejor se encomienden a la memoria. Constituye un fascículo de doce hojas con 720 preguntas sin respuesta escritas totalmente en versos pareados, impreso en $1539^{30}$.

27 Así lo apunta Sanz Hermida, J., ed. (2001), Cuatro tratados médicos renacentistas sobre el mal de ojo, Valladolid, Junta de Castilla y León, Consejería de Educación y Cultura, p. 64. En la introducción trata fragmentos de obras del género de preguntas y respuestas que recogen el mal de ojo (pp. 64-66). Dos de los cuatro textos latinos que edita y traduce presentan fragmentos en forma de pregunta y respuesta: el Tractatus de fascinatione (¿1499?), del sevillano Diego Álvarez Chanca, médico que acompañó a Cristóbal Colón en su segundo viaje a las Indias (pp. 73-140) y las Relectiones de fascinatione (1561) de Tomás Rodrigues da Veiga (1513-1579), uno de los médicos portugueses más prestigiosos de su época (pp. 257287). Sobre este tema y alguno de estos textos, véase SALMÓN, F., y CABRÉ, M. (1998), «Fascinating Women: The Evil Eye in Medical Scholasticism», en FrEnCH, R., ARrizabalagA, J., Cunningham, A., y García Ballester, L., eds., Medicine from the Black Death to the French Disease, Aldershot, Ashgate, pp 53-84.

28 Sobre López de Corella y su obra, véase SANz Hermida (1993). López de Corella tenía conciencia de crear un nuevo estilo, como atestigua en los Secretos de filosophía: «Y juntamente vean que yo he sido el primero que en este estilo me he puesto a escrevir esta materia. Y conforme al dicho de Galeno, secundo libro De facultativus naturalibus, «no es posible que uno principie un género de escrevir y lo perfecione.» (p. 195).

29 Estos datos en Gurpegui Resano, J.R. (2001), Alonso López de Corella (c. 15191584) y el libro De Morbo Pustulato (1584), una monografia sobre el tabardillo, tesis doctoral de la Universidad de Navarra.

30 Gurpegui Resano (2001) valora los Secretos así: «Debe ser interpretada como la obra de quien, mientras prepara su licenciatura, ocupa sus ocios elaborando un listado de diversos 
Dándose cuenta de que la ausencia de respuestas dificultaba la comprensión de la obra ${ }^{31}$, emprendió una nueva versión en la que se proponía, «condescendiendo a ruego de muchos amigos, responder a las preguntas pasadas, pues ellos, por no saber philosophía y otras sciencias que se requieren, no las entienden ${ }^{32}$. De este modo, en 1546 se imprimieron 309 de los problemas de la obra anterior con las respuestas en verso y una glosa en prosa, con el título de Trezientas preguntas de cosas naturales en diferentes materias con las respuestas $y$ alegaciones de auctores, las quales fueron antes preguntadas, a manera de perqué por el Licenciado Alonso Lopez de Corella, médico. Y agora por él mesmo respondidas y glosadas en este año de $1546^{33}$.

Considerando López de Corella que la obra impresa en Valladolid en 1546 contenía demasiados errores producto de la prisa del editor, ${ }^{34}$ en 1547 se imprimió en Zaragoza la que debe considerarse como la edición definitiva y autorizada de su obra. Son los Secretos de Philosophía y Astrología y Medicina y de las quatro mathemáticas Sciencias, collegidos de muchos y diversos auctores, y divididos en cinco quinquagenas de Preguntas por el Licenciado Alonso López de Corella, médico. Contiene 250 preguntas en verso con las respectivas respuestas también versificadas ${ }^{35}$, seguidas de comentarios en prosa más amplios que los de la edición de $1546^{36}$. La dependencia de la obra

problemas de Filosofía Natural: una especie de memorandum de lo que todo bachiller en Artes debe conocer antes de su graduación» (p. 206).

31 Que había escrito sin respuesta ya que "para los doctos no es más menester/ y a los que no saben basta el proponer/ para a preguntarlas les dar afición», en GURPEGUI RESANO (2001), p. 189.

32 Gurpegui Resano (2001), p. 189.

33 De esta impresión, realizada en Valladolid, existe edición moderna: CRUZ CRUZ, J., ed. (2000), Alonso López de Corella, Trescientas preguntas de cosas naturales (1546), Pamplona, Universidad de Navarra, con un prólogo («López de Corella: un dietista del vino») que situa a López de Corella en el contexto médico universitario de su época. SANZ HermidA (1993), analiza la relación de las obras de López de Corella entre sí y los problemas de edición de ésta de 1546, considerada falsa por el propio López de Corella.

34 «Suplico pues al lector que no tenga por mío aquel tractado y sepa que por satisfazerle acerca desto he dado más priessa a imprimir esta obra que la materia requería», en SANZ HERMIDA (1993), p. 192.

35 Las respuestas son dos quintillas dispuestas en forma de cobla real, una copla de arte menor o una copla mixta, según CUARTERO SANCHO (1990), p. 224.

36 También existe edición moderna de esta obra: Cruz Cruz, J., ed. (2001), Alonso López de Corella, Secretos de filosofía y astrología y medicina y de las cuatro matemáticas ciencias, colegidos de muchos y diversos autores y divididos en cinco quinquagenas de preguntas, Pamplona, Gobierno de Navarra, Departamento de Educación y Cultura. 
de este médico navarro con la tradición de los Problemas de Aristóteles no ofrece ninguna duda. Las Trezientas preguntas... contienen una lista de «los autores principales donde estas preguntas se han colegido», entre los cuales figuran Aristóteles y Alejandro de Afrodisia ${ }^{37}$, autores que también son citados como autoridades en su obra De vini commoditatibus (Zaragoza, 1550) ${ }^{38}$.

El dramaturgo soriano Hernán López de Yanguas (1487-ca. 1540) (19 $^{39}$ escribió en verso ${ }^{40}$ las Cincuenta bivas preguntas con otras tantas respuestas, que se imprimieron en tres ocasiones durante el siglo XVI y una en el XVII ${ }^{41}$. En el preámbulo de la obra, el autor anuncia sus fuentes, que son Aristóteles, Plutarco y Alejandro de Afrodisia:

Obra nuevamente compuesta por el bachiller Hernán López de Yanguas, llamada Problemas, que quiere decir preguntas con sus respuestas. La cual, por no estar ocioso, compuso a imitación de Aristóteles y de Plutarco y de Alejandro Afrodiseo, de cuyas entrañas manó, para provecho y utilidad y pasatiempo de los

37 CRUZ CRUZ (2000), p. 87.

38 JimÉnez Delgado, J., ed. y trad. (1978), Alonso López de Corella, Las ventajas del vino, Pamplona, Diputación Foral de Navarra-Institución Príncipe de Viana-CSIC: «Aristoteles enim testatur trigesima sectione problematum» (72), «Ut enim Aristoteles est autor trigesima sectione problemate primo multiiuge sunt ebrietatis species» (102), "Quod euenire solet, teste Alexandro aphrodiseo sectione quarta problematum» (80).

39 Sobre López de Yanguas como autor de teatro véase GonZÁlez OllÉ, F., ed. (1967), Fernán López de Yanguas, Obras dramáticas, Madrid, Espasa-Calpe; y PÉREZ-RIOJA, J.A. (1968), Hernán López de Yanguas, humanista y autor dramático, Soria, Centro de Estudios Sorianos.

40 En redondillas de rima cruzada y abrazada, según CUARTERO SANCHO (1990), p. 226.

41 En Medina del Campo, ca. 1540 y ca. 1543, Valencia, 1550, y Barcelona, 1618. El libro, de 16 folios, empieza con esta redondilla: «Aquí lector verás juntas/ por Hernán López compuestas/ cincuenta vivas preguntas/ con otras tantas respuestas.» Al dorso: «Obra nuevamente com-/ puesta por el Bachiller/ Hernán López de Yan-/ guas: llamada Proble-/ mas, que quiere dezir/ preguntas con sus res-/ puestas», ed. GonZÁlEZ Ollé (1967), pp. XVIII-XIX. Véase PAlAu i Dulcet, A. (1948-1977), Manual del librero hispano-americano: bibliografia general española e hispano-americana desde la invención de la imprenta hasta nuestros tiempos, con el valor comercial de los impresos descritos, 38 vols. Barcelona, Librería Anticuaria de A. Palau-Oxford, The Dolphin Book, vol. 7, p. 671, que transcribe «Cincuenta buenas preguntas». Tanto en el Catálogo colectivo de obras impresas en los siglos XVI al XVIII existentes en las bibliotecas españolas, sección I (siglo XVI), 15 vols., Madrid, Instituto Bibliográfico Hispánico, 1972-1984 (ed. provisional), vol. Letras L-LL (1976), §. 1252-1254; como Thomas, H. (1921, $2^{\text {a }}$ ed. 1966), Short-Title Catalogue of Books Printed in Spain and of Spanish Books Printed Elsewhere in Europe Before 1601 Now in the British Museum, Londres, Bristish Museum, p. 54, se transcribe el título correctamente. 
lectores, no poca parte de lo que en ella se trata. Finge la obra a manera de diálogo que dos personas, estando ociosas en las largas noches de invierno, la una llamada Deseo y la otra Reposo, para pasar tiempo, acordaron que el uno preguntase y el otro respondiese todas las preguntas y respuestas que aquí se tratan, en las cuales hay muchos secretos y vivezas tocantes a la natural filosofía, según el benigno y docto lector podrá ver ${ }^{42}$.

De la difusión de la obrita de López de Yanguas son testimonio las tres ediciones citadas y las palabras del humanista y pedagogo Juan Lorenzo Palmireno (ca. 1514-1580) ${ }^{43}$, que prueban que el texto se utilizaba como manual en las aulas. En El estudioso de la aldea (Valladolid, 1568), Palmireno aconseja que para descansar de los ejercicios de sintaxis y no estar ocioso, se podía perfectamente

cantar alguna copla de aquel libro que se dice Cincuenta preguntas, del Bachiller Hernán López de Yanguas, impresso en Valencia, 1550. Con seis dineros que te costará, aprenderás burlando, y con pasatiempo, cosas que te harán docto poco a poco ${ }^{44}$.

El también poeta Francisco López de Villalobos (ca. 1473-1549), de origen judío, estudiante en Salamanca ${ }^{45}$ y luego médico (y astrólogo) que alcanzó un gran prestigio profesional y social - estuvo al servicio de los duques de Alba, de Fernando el Católico y de Carlos V-46, escribió el Libro intitulado Los problemas, que trata de cuerpos naturales y morales. Escrito en coplas castellanas seguidas de una glosa en prosa, se imprimió en cinco ocasiones, la primera en $1543^{47}$. Los Problemas de Villalobos ${ }^{48}$, título con el que se conoce

42 Citamos según el ejemplar de Madrid, BN, R 8839, f. Iv, que corresponde a la edición de Valencia de 1550. Este fragmento también lo recoge CuARTERO SANCHO (1990), p. 225.

43 Autor que utiliza también el procedimiento de pregunta y respuesta en su Silva de vocablos y frases de moneda, medidas, comprar y vender para los niños de gramática (Valencia, 1563), según apunta CUARTERO SANCHO (1990), p. 222.

44 GonZÁlez Ollé (1967), p. X.

45 Sobre los estudios de medicina en la Universidad de Salamanca, véase PÉREZ IBÁÑEZ, M‥ J. (1998), El humanismo médico del siglo XVI en la Universidad de Salamanca, Valladolid, Universidad de Valladolid, esp. pp. 70-73; y GARCÍA BALLESTER (2001), cap. 3.

46 Sabemos que también ejerció de médico en Zamora. Sobre la biografía de López de Villalobos, véase el capítulo de GrANJEL, M. «El licenciado López de Villalobos» en SÁNCHEZ Granjel et al. (1998), pp. 17-35; y también ARRIZABAlaGA, J. (2002), "Francisco López de Villalobos (c.1473-c.1549), médico cortesano», Dynamis, 22, 29-58.

47 Libro intitulado Los problemas que trata de cuerpos naturales y morales, y dos diálogos de medicina, y el tratado de las tres grandes, y una canción, y la comedia de Amfitrión, 
esta obra de gran éxito y difusión, dedicada al infante don Luis de Portugal, contienen dos tratados. El primero (con seis problemas) trata de los cuerpos naturales y el segundo (con treinta y cinco) de las «cosas morales, conviene a saber, del hombre y de sus costumbres y maneras» ${ }^{49}$. Las preguntas, en verso, son muy breves, y las respuestas, en prosa, bastante más largas, posiblemente porque el autor las considera lo esencial de su obra ${ }^{50}$. Villalobos apenas incluye citas de autoridades en su obra, cuya vinculación con los Problemas de la tradición aristotélica parece depender más de la forma que del contenido, puesto que el médico y poeta intercala con gracia notícias biográficas y críticas a la sociedad de su tiempo. Sírvanos el metro 24 del segundo tratado como ejemplo:

\author{
¿Por qué el físico doliente \\ Del mal que en sí nunca sana \\ Promete de buena gana \\ La salud a otro paciente? \\ Mándale al triste que coma \\ Lo que él no quiere tragar, \\ Y las purgas que él no toma \\ $\mathrm{Al}$ otro manda tomar.
}

con ediciones impresas en Zamora, 1543, Zaragoza, 1544, y Sevilla, 1550 y 1574. LóPEZ PIÑERO, J.Ma ., et al. (1981-1986), Los impresos científicos españoles de los siglos XV y XVI: inventario, bibliometría y thesaurus, 4 vols. en 3 tomos, Valencia, Universidad de Valencia, vol. 2-3, pp. 166-167. PALAU i Dulcet (1948-1977), vol. 7, p. 670, cita además una edición impresa en Sevilla en 1570. Los dos diálogos de medicina son el Diálogo de las fiebres interpoladas y el Diálogo del calor natural, obras que Villalobos redactó un cuarto de siglo antes, pero que se publicaron por primera vez junto con los Problemas. En el Tratado de las tres grandes, López de Villalobos habla «de la gran parlería, de la gran porfía y de la gran risa». Tradujo el Amphitrion de Plauto en 1515. Sus Congressiones vel duodecim principiorum liber nuper editus (Salamanca, 1514) fueron traducidas al inglés en el siglo XIX: GASKOIN, G. (1870), The Medical Works of Francisco López de Villalobos, the Celebrated Court Physician of Spain, Now First Translated With Commentary and Biography, Londres, J. Churchill \& Sons.

48 ARIBAU, B.C., ed. (1855), Los problemas de Villalobos, Madrid, M. Rivadeneyra (Biblioteca de autores españoles, XXXVI, Curiosidades bibliográficas), pp. 403-493. El título entero es Libro intitulado Los problemas de Villalobos, que tracta de cuerpos naturales y morales; y dos diálogos de medicina y el tratado de las tres grandes, y una canción, y la comedia de Anfitrión. Después de la Canción de Villalobos y la glosa (p. 460) se lee: «Fin de los problemas de Villalobos».

49 ARIBAU (1855), p. 405.

50 «Lo mejor de la obra (si algo tiene de bueno) es la glosa; los metros son como compendios y sumarios de lo que en ella se tracta», en ARIBAU (1855), p. 404. 


\section{GLOSA}

Esta copla está muy clara y no tiene respuesta; porque, si este médico piensa que no puede sanar al otro, ¿por qué le cura y por qué le da tantas hieles a beber? Et si piensa que le puede sanar, ¿por qué no se cura a si mesmo? Que más obligado es a sí que a los otros. Mas dejando aparte la maldad del médico, cosa es para reír la necedad del paciente. Yo vi en Montpeller un físico que llamaban maestre Falcon, y era tan sordo, que no podía oír campanas ni trompetas, y todos los que ensordecían por aquellas tierras se venían a curar con él, porque decían que conoscía bien la enfermedad, y esto parescía a ellos que bastaba, aunque volviesen a sus casas mucho más sordos que cuando salieron dellas ${ }^{51}$.

El médico y naturalista Juan de Jarava ${ }^{52}$, que residió largo tiempo en Lovaina y fue médico de Leonor, hermana del emperador Carlos $\mathrm{V}$ y reina de Francia, publicó en 1544 una obra en prosa que lleva por título Problemas o preguntas problemáticas, ansí de amor como naturales y acerca del vino ${ }^{53}$. El autor asegura estar realizando una traducción del latín, aunque confiesa haber manipulado el original, de acuerdo con la tradición propia de la literatura de problemas. No debemos olvidar aquí que, en la Edad Media, 'escribir' —acto que incluía tambén la traducción tal como hoy la entendemos- significaba reescribir y actualizar a los auctores de la propia tradición con el objeto de inscribirse en ella ${ }^{54}$. He aquí el testimonio de Jarava:

51 ARIBAU (1855), p. 423.

52 Véase PAlau i Dulcet (1948-1977), vol. 4, p. 121, y Enciclopedia universal ilustrada europeo-americana (1908-1930, reimpr. 1975-1999), 72 vols. con supl., Madrid, EspasaCalpe, s. v. «Jarava», donde se relacionan las obras de este personaje. Sobre Juan de Jarava, véase GARCÍA PINILLA, I.J. (1995), «On the Identity of 'Juan de Jarava, medico y philosofo'», Bibliothèque d'Humanisme et Renaissance, 57, 45-66; LÓPEZ PIÑERO, J.Mª., LÓPEZ TERRADA, $\mathrm{M}^{\mathrm{a}}$.L., et al. (1994), La traducción por Juan de Jarava de Leonhart Fuchs y la terminología botánica castellana del siglo XVI, Valencia, Universidad de Valencia-CSIC, Instituto de estudios documentales e históricos sobre la ciencia; PARDO TOMÁS, J. (1998), «Introducción», en Leonhart Fuchs, Historia de las yervas y plantas: un tratado renacentista de materia médica, Barcelona, Edicions Joan de Serrallonga.

53 Problemas o preguntas problemáticas, ansi de amor como naturales y acerca del vino, vueltas nuevamente de latín en lengua castellana y copiladas de muchos y graves authores por el maestro Juan de Jarava, médico. Éste es el título de la segunda edición, impresa en Alcalá de Henares en 1546. PALAU i DULCET (1948-1977), vol. 4, p. 121, apunta la existencia de una edición anterior, de 1544, no conservada, dato que es corroborado por el propio texto de 1546 cuando se indica que «lo que de nuevo se ha añadido a la primera impresión es lo siguiente»: «la alabança de la pulga» y «la ymagen del silencio y descripción de lo que sus partes representan» (f. I). El volumen contiene también una traducción del Icaromenipo de Erasmo. Véase BATAILLON, M. (1950²), Erasmo y España, Madrid, Fondo de Cultura Económica, p. 643.

54 Véase Copeland, R. (1991), Rhetoric, Hermeneutics and Translation in the Middle Ages: Academic Traditions and Vernacular Texts, Cambridge, Cambridge University Press. 


\section{ANTÒNIA CARRÉ y LLUÍS CIFUENTES}

$\mathrm{Y}$ es cierto que en traduzir estos problemas o demandas que no he estado tan atado al pie de la letra que no haya mudado o trastocado alguna cosa, o añadido alguna causa y verso acotado de algún autor al propósito, y también he dexado alguna razón que no hazía mucho al caso ${ }^{55}$.

Dividido en tres partes, y tal como indica su título completo, la obra contiene preguntas, con sus correspondientes respuestas, relativas al amor, a las cuestiones naturales y otras acerca del vino, con una elaborada mezcla de los temas característicos (filosofía e historia naturales, fisiognomía, etc.) de los libros de problemas de raíz aristotélica ${ }^{56}$. Aunque tenemos pocos datos sobre su autor ${ }^{57}$, éste se dibuja como un personaje interesante. Traductor de Cicerón y partidario de las ideas erasmistas, tradujo al castellano (1549) los Apotegmas de Erasmo ${ }^{58}$, florilegio escrito por el de Rotterdam en $1531^{59}$. Juan de Jarava fue autor también de un tratado divulgativo sobre filosofía natural que tiene como fuente principal a Aristóteles, impreso en Amberes en 1546 y traducido al italiano por Alonso de Ulloa en $1557^{60}$.

Fray Luis de Escobar ${ }^{61}$ planeó escribir tres colecciones de preguntas y respuestas, pero tan sólo pudo llevar a cabo las dos primeras. Las quatrocientas

55 Citamos según el ejemplar de la edición de Alcalá de Henares de 1546 conservado en Madrid, BN, R 14294, f. IIIIV.

56 Aristóteles es una autoridad citada directamente (por ejemplo, ff. LIV y LII), y las preguntas sobre el vino insisten en la embriaguez, como en los Problemata pseudoaristotélicos. Lo mismo harán López de Corella y Girolamo Manfredi.

57 Picatoste Rodríguez, F. (1891), Apuntes para una biblioteca científica española del siglo XVI, Madrid, Manuel Tello [reimpr. facs. (1999), Madrid, Ollero \& Ramos], p. 157, apunta: «Sólo sabemos de este naturalista que residió mucho tiempo en Lovaina, y que fué médico de Eleonora, reina de Austria».

58 Con el título de Libro de vidas y dichos graciosos, agudos y sentenciosos, de muchos notables varones griegos y romanos, ansí reyes y capitanes, como philósophos y oradores antiguos, en los quales se contienen graves sentencias e avisos no menos provechosos que deleytables, impreso en Amberes en 1549. Citamos según el ejemplar de Madrid, Real Academia Española, 14-XI-60.

59 Véase BATAILlON $\left(1950^{2}\right)$, pp. 627-628. Sobre las traducciones de Cicerón, véase la p. 625.

60 La Philosophía natural brevemente tratada y con mucha diligencia copilada de Aristóteles, Plinio, Platón y otros grandes autores hasta agora nunca visto en lengua española. Véase PAlau i Dulcet (1948-1977), vol. 4, p. 121. Hijo de un oficial que estuvo en África con Carlos V, Alfonso de Ulloa abandonó el ejército al establecerse en Venecia, donde residió hasta su muerte ( $c a$. 1580). En la ciudad de los canales desempeñó trabajos diplomáticos y se dedicó a la traducción de autores españoles y portugueses al italiano. Véase Enciclopedia universal ilustrada europeo-americana, s. v. «Ulloa, Alonso de».

61 Pocos datos hemos sabido encontrar de este poeta y religioso de la orden de los franciscanos. Véase Enciclopedia universal ilustrada europeo-americana, s. v. «Escobar, Luis de». 
respuestas a otras tantas preguntas que D. Fadrique Enríquez y otras personas en diversas vezes embiaron a preguntar al autor, que no quiso ser nombrado, mas de cuanto era fraile menor, con quinientos proverbios de consejos $y$ avisos por manera de letanía, se imprimieron en cinco ocasiones, la primera en $1545^{62}$. Esta primera colección, que contiene una primera parte en verso ${ }^{63}$, trata fundamentalmente de temas teológicos, pero incluye también algunas cuestiones de filosofía natural ${ }^{64}$.

La segunda colección de Luis de Escobar se publicó en Valladolid en 1552 con el título de La segunda parte de las Quatrocientas respuestas en que se contienen otras quatrocientas respuestas a otras tantas preguntas al mesmo auctor, assí en prossa como en metro, con cincuenta declaraciones o glosas en los lugares que paresció ser más menester, por el mismo auctor ${ }^{65}$. Escobar indica, en una de las preguntas de filosofía natural, cual es su fuente directa:

\author{
Aristóteles compone \\ esas cuestiones y temas, \\ y en uno de sus problemas \\ la misma pregunta pone ${ }^{66}$.
}

62 Valladolid 1545, Zaragoza 1545 (dos), Valladolid 1550, y Amberes 1546-1550. Véase PAlau i DulCET (1948-1977), vol. 5, pp. 97-98; Catálogo colectivo de obras impresas en los siglos XVI y XVII, vol. Letras E-F (1974), § 626-632; SÁNCHEZ, J.M. (1913-1914), Bibliografía aragonesa del siglo XVI, 2 vols., Madrid, Impr. Clásica Española, vol. 2, § 248. Tal como señala Palau, el nombre del autor, que no figura en el título, consta en un acróstico de la «Invocación a la letanía».

63 Las preguntas en verso, con una notable variedad estrófica que incluye quintillas, coplas mixtas, redondillas abrazadas, coplas de arte mayor, cuartetos de rima cruzada y abrazada (CUARTERo SANCHO, 1990, p. 229), llegan al f. CXI, a partir del cual el texto se desarrolla en prosa. Hemos consultado el ejemplar de la Biblioteca de la Universitat de Barcelona, B. 14-413-2345, que corresponde a la primera edición de Zaragoza.

64 Preguntas $n^{\circ} .218$ a 268 de la segunda parte de esta colección. También las preguntas $\mathrm{n}^{\circ} .269$ a 324 del apartado de «doctrinas morales» (CUARTERO SANCHO, 1990, p. 229).

65 Palau i Dulcet (1948-1977), vol. 5, p. 98; Catálogo colectivo de obras impresas en los siglos XVI y XVII, vol. Letras E-F (1974), § 633; THOMAS (1921, $2^{\text {a }}$ ed. 1966), p. 32. Hemos consultado el ejemplar de la Biblioteca de la Universitat de Barcelona, B. 19-2-173036. La métrica usada es la misma que en la primera colección, con el añadido de la copla manriqueña. A partir de la pregunta 251, pregunta y respuesta van en prosa (CUARTERO SANCHO, 1990, p. 231).

66 La segunda parte de las Quatrocientas respuestas..., f. 105, en CUARTERO SANCHO (1990), p. 232. 
El médico de Segovia Agustín de Ruescas ${ }^{67}$ escribió un Diálogo en verso, intitulado Centiloquio de problemas ${ }^{68}$, una colección de cien preguntas y respuestas en verso ${ }^{69}$ con notas marginales en latín sobre las fuentes utilizadas, que se imprimió en Alcalá de Henares en 1546. El diálogo que mantienen los 'filósofos' Pánfilo y Protidemo está basado fundamentalmente en los Problemas de Aristóteles ${ }^{70}$, pero también ${ }^{71}$ en el comentario de Pietro d'Abano, los Problemas de Alejandro de Afrodisia, los Problemas del portugués Antonio Luiz $^{72}$ y el Problema de Erasmo ${ }^{73}$.

El poeta sevillano Alonso de Fuentes (1515- ca. 1550) ${ }^{74}$ fue autor de una Summa de philosophía natural, una nueva colección de problemas, esta vez con las preguntas en verso y las respuestas en prosa, que se imprimió en Sevilla en 1545 y en $1547^{75}$. El argumento de la obra es el siguiente: Etrusco, un

67 El autor, que en el prefacio de la obra declara encubrir su nombre por propia decisión, se identifica en el acróstico de las octavas: «El licenciado Agustín de Rruescas, médico segoviense, hizo este Centiloquio», en CUARTERo SANCHO (1990), p. 233.

68 Diálogo en verso, intitulado Centiloquio de problemas, en el qual se introduzen dos philósophos, el uno Pámphilo llamado, que cient philosóphicas preguntas propone, y el otro Protidemo, que respondiendo suscintamente las dissuelve. Obra muy útil y provechosa de varia y singular erudición, do se contienen muchos secretos y bivezas tocantes a la natural Philosophía. Véase LóPEZ PIÑERo et al. (1981-1986), vol. 4, pp. 24-25. PALAu i Dulcet (1948-1977), vol. 18, p. 87, recoge el acróstico y apunta la existencia de una edición impresa en Alcalá en 1548, dato que se ha demostrado erróneo. Utilizamos el ejemplar conservado en Madrid, BN, R. 31229.

69 Coplas reales y coplas manriqueñas (CUARTERO SANCHO, 1990, p. 233).

70 «Argumento de este dialogal Centiloquio. Saliendo un día Pámphilo a espaciarse, mancebo de singular ingenio dotado, y en la philosóphica disciplina medianamente instruydo, halló a caso en un deleytoso valle a Protidemo, varón claro y erudito, que a la sazón cierta materia en los problemas de Aristóteles mirava. Donde viendo Pámphilo la opportunidad del tiempo que conforme a su desseo y natural inclinación se ofrecía, pide a Protidemo le declare algunas philosophales dudas». Citamos a partir del ejemplar de Madrid, BN, R 2217, f. 7.

71 Así lo apunta CuArTero SANCHO (1990), p. 234.

72 Sobre los Problemata (1540) de este médico de Lisboa, véase LAWN (1963), pp. 132, 134 y 138.

73 Forma parte de sus Colloquia familiaria (1518-1526). Véase CUARTERo SANCHO (1990), p. 221.

74 Sobre este rimador de crónicas (es autor de un Libro de los cuarenta cantos en verso y prosa) véase Gran Enciclopedia de Andalucía (1979), 10 vols., Sevilla, Promociones culturales andaluzas, s v. «Fuentes, Alonso de»; Alborg, J.L. (1966, 2 ${ }^{\mathrm{a}}$ ed. 1992), Historia de la literatura española, Madrid, Gredos, vol. 1, pp. 315 y 405; y SANZ HERMIDA (1997).

75 López PiÑERo et al. (1981-1986), vol. 2-3, p. 52. CUARTERo SANCHO (1990), no cita esta obra. 
noble de la Toscana, pasea por Sevilla, a orillas del Guadalquivir, cuando se encuentra con Vandalio, un andaluz que le hace preguntas para instruirse en filosofía, astronomía, astrología, el alma y la anatomía del cuerpo humano y la generación humana. A pesar de que sólo nos consta la existencia de una edición castellana, esta obra debió gozar de popularidad puesto que fue traducida al italiano por Alonso de Ulloa y se imprimió en esta lengua en dos ocasiones (Venecia, 1557 y 1567$)^{76}$.

Jerónimo Campos, en su Sylva de varias questiones naturales y morales, que se imprimió en Amberes en 1575 y en Valencia en 158777, imitó la colección de problemas del italiano Ortensio Lando (ca. 1512-ca. 1553), hecho que seguramente debió determinar que usara exclusivamente la prosa ${ }^{78}$. En el «Prólogo del autor», Campos expone los motivos que le llevaron a elaborar su obra, y aclara que se trata de una traducción realizada con afán divulgativo ${ }^{79}$ :

Y assí, viéndome desocupado de algunos negocios civiles, quise bolver a mis estudios, y rebolviendo mis papeles topé con un gran número de questiones naturales y morales, que de graves auctores tenía recogidos, y assí quise (dándoles las soluciones según que sabía) sacarlas en romance, y hazer un libro, con el qual, los

76 Véase LÓPEZ PIÑERO et al. (1981-1986), vol. 2-3, p. 53. La primera edición se imprimió con el título de Somma della Natvral Filosofia di Alfonso di Fonte divisa in dialoghi sei... novellamente tradotta di Spagnvolo in volgare de Alfonso di Vlloa. La segunda como Le sei giornate del $S$. Alfonso di Fonte nelle quali oltre le materie di Filosofia s'ha piena cognitione delle scienze, astronomia et astrologia, dell'Anima, e della Notomia del corpo humano. Nuovamente di lingua spagnuola tradotte dal S. Alfonso Ulloa. Hemos visto el ejemplar de la Biblioteca de la Universitat de Barcelona, XVI-3342. La traducción italiana es exclusivamente en prosa.

77 JERÓNIMO CAMPOS, Sylva de varias questiones naturales y morales, con sus respuestas y soluciones, sacadas de muchos auctores griegos y latinos. Véase PALAU I DULCET (19481977), vol. 3, p. 88; LóPEZ PIÑERo et al. (1981-1986), vol. 1, p. 92. CUARTERo SANCHO (1990), no cita esta obra.

${ }_{78}$ Ortensio Lando escribió en latín las Miscellaneae questiones (Venecia 1550), que luego tradujo al italiano con el título de Quattro libri de dubbi con le solutioni a ciascun dubbio accommodate. La materia del primo e naturale, del secondo e mista (benche per lo piu sia morale) del terzo e amorosa, \& del quarto e religiosa, obra impresa en Venecia en 1552. LAWN (1963), pp. 101 y 139. Sobre el autor, véase MELZI (1848-1859+supl.), vol. 2, p. 391.

79 Hemos consultado el ejemplar de la Biblioteca de la Universitat de Barcelona, B. 3-57-311, que corresponde a la edición de Valencia de 1587. Esta edición contiene, antes del prólogo del autor, las acostumbradas licencias de impresión, ambas en catalán: primero, la licencia real, firmada por el marqués de Aitona, Francesc de Montcada, lugarteniente y capitán general del reino de Valencia; y, a continuación, la licencia eclesiástica, firmada por Antoni Galant, doctor en teología. 


\section{ANTÒNIA CARRÉ y LLUÍS CIFUENTES}

que no han professado muchas sciencias, supiessen responder y satisfazer a muchas dudas que se les offrece. De manera que ésta es la causa porque quise hazer este libro o sylva: de los arboles buenos que en ella hay coged el fruto mejor y que más se conformare al gusto de vuestro paladar ${ }^{80}$.

La obra está dividida en dos «libros» (sobre la filosofía natural y la filosofía moral, respectivamente), que contienen a su vez siete «centurias» cada uno, organizadas en las correspondientes «questiones» y «soluciones». El libro primero presenta una mezcolanza de temas propios de las seis 'cosas no naturales' del galenismo, habituales en todos los regímenes de salud ${ }^{81}$, junto con otros relacionados con el conocimiento del mundo físico. Algunos de los temas tratados por Jerónimo Campos son los siguientes ${ }^{82}$ :

Centuria primera: las complexiones, el nombre de la tierra, el mar, etc.

Centuria segunda: las aves, la luna, el fuego, los meses del año, los pelos, la peste, etc.

Centuria tercera: la mujeres y el parto, algunos animales, el vino, el esperma, etc.

Centuria cuarta: el agua, las almendras, el ejercicio, el aire, etc.

Centuria quinta: el ayuno, las hierbas, el cerebro, etc.

Centuria sexta: el sueño, los ojos, algunos otros animales, los niños, etc.

Centuria séptima: el oro, las piedras preciosas, la miel, los borrachos, etc.

Nos consta la existencia de otro libro de problemas en castellano, del que no hemos podido localizar ningún ejemplar. Se trata de la obra de Juan Gon-

80 La metáfora del alimento asociada al aprendizaje era habitual ya en la Edad Media. El Marqués de Santillana, por ejemplo, assegura en su Proemio e carta que la poesía és «un insaciable cibo del ánimo» (GARCI-Gómez, M., ed., 1984, Marqués de Santillana, Prohemios $y$ cartas literarias, Madrid, Editora Nacional, p. 187) y así hay que entender, a grandes rasgos, el Convivio de Dante (tratado 2, cap. 1).

81 Sobre el origen y la evolución de este concepto médico, véase RATHER, L.I. (1968), "The 'six things non-natural': A note on the origins and fate of a doctrine and a phrase», Clio Medica, 3, 337-347; y GARCíA BALLESTER, L. (1993), «On the origin of the 'six non-natural things' in Galen», en Kollesch, J., y Nickel, D., eds., Galen und das hellenistiche Erbe, Stuttgart, F. Steiner, pp. 105-115. La más completa exposición sobre el género médico de los regimina sanitatis es el estudio introductorio de GIL SOTRES, P. (1996), en García Ballester, L., Mcvaugh, M.R., Gil Sotres, P., y Paniagua, J.A., eds., [Arnaldi de Villanova] Regimen sanitatis ad regem Aragonum, en García Ballester, L., Mcvaugh, M.R., y Paniagua, J.A., eds., Arnaldi de Villanova Opera Medica Omnia, vol. X.1, Barcelona, Universitat de Barcelona-Fundació Noguera.

82 Consultamos el ejemplar de la Biblioteca de la Universitat de Barcelona, B. 3-5-7-311; el segundo libro, dedicado a las cuestiones morales, empieza en la p. 114. 
zález de la Torre titulada Doscientas preguntas con sus respuestas en versos diferentes (Madrid, 1590) ${ }^{83}$, que contiene doscientos trece enigmas con sus respectivas soluciones. En realidad, esta obra se inscribe en el marco de las compilaciones misceláneas ${ }^{84}$, género didáctico con afán divulgativo que el humanismo renacentista hizo triunfar ${ }^{85}$. Una buena muestra del enorme éxito de este género, en el que se combina la exposición de diversos temas que resultaban atractivos para un público no académico con relatos divertidos relacionados con los exempla, son las 107 ediciones en distintas lenguas de la Silva de varia lección de Pedro Mexía, miscelánea que se imprimió por primera vez en Sevilla en $1540^{86}$.

La estructura de los libros de problemas se filtra en otro tipo de textos, como ocurre por ejemplo en un fragmento del Compendio de la humana salud (Zaragoza, 1494), traducción del florilegio latino anónimo de textos médicos, quirúrgicos y recetas que obtuvo gran éxito en la Europa central con el título de Fasciculus medicinae (1491) ${ }^{87}$. En su apartado dedicado a las «do-

83 Recogida por PALAu I Dulcet (1948-1977), vol. 6, p. 306, que apunta que es una obra rara y no localiza ningún ejemplar, pero señala que «Salvá poseyó ejemplar en gran papel». Salvá Mallén, P. (1872), Catálogo de la Biblioteca de Salvá, 2 vols., Valencia, Impr. de Ferrer de Orga, 1872 [reimpr. facs. (1993), Valencia, Libr. París-Valencia], lo incluye entre las obras de paremiología, con el siguiente comentario: «Docientas preguntas con sus respuestas en versos diferentes. Compuestas por Juan Gonçalez de la Torre. Van ansimismo otras Glosas, y versos de devoción, algunas tocantes á la doctrina Christiana. Y la vida del glorioso San Francisco de Paula, instituydor del Orden de los Mínimos, y algunos de sus milagros. Y otros motes, y villancicos de devoción. Compuestos por el mismo Autor. Madrid, Francisco Sanchez, 1590. $4^{\circ} »$. Y añade: «Mi ejemplar es hermoso y en gran papel, y es libro mui raro, aun en papel ordinario» (vol. 2, p. 208).

84 CUARTERo SANCHO (1990), p. 234, señala que la obra en cuestión no pertenece propiamente al género de los problemas y la incluye en el de las misceláneas, junto con la Filosofía vulgar de Juan de Mal Lara (Sevilla, 1568). Sobre esta glosa de refranes, que no está estructurada en forma de preguntas y respuestas, véase ViLANOVA, A., ed. (1958), Juan de Mal Lara, Filosofia vulgar, 3 vols., Barcelona, Selecciones Bibliófilas, $2^{\mathrm{a}}$ serie.

85 Para una visión panorámica del género de las misceláneas escritas en castellano, véase RALLO GRUSS, A. (1984), «Las misceláneas: conformación y desarrollo de un género renacentista», Edad de Oro, 3, 159-180.

86 Silva de varia lección en la qual a manera de silvas sin guardar orden en los propósitos, se tratan por capitulos muchas y muy diversas materias, historias, exemplos y questiones de varias lección y erudición. De esta obra, que incluye temas médicos y de filosofía natural en su contenido, constan 32 ediciones castellanas. Fue traducida al italiano (30 ediciones), al francés (31), al inglés (5), al holandés (5) y al alemán (4). Véase CASTRO, A., ed. (1989), Pedro Mexía, Silva de varia lección, Madrid, Cátedra.

87 El texto latino, que se imprimió en 1491, fue traducido al italiano también en 1494 con el título de Fasciculo de medicina in volgare. Existen dos traducciones castellanas de la obra, 
lencias de las mujeres» contiene preguntas y respuestas procedentes del $\mathrm{Om}$ nes homines, una de las tradiciones textuales de los Problemata Aristotelis ${ }^{88}$.

Es en este contexto ibérico del siglo XVI, definido por una gran proliferación de las colecciones de problemas, que hay que situar la traducción castellana del Liber de homine, más conocido como Il perché, del italiano Girolamo Manfredi, realizada por Pedro de Ribas e impresa por primera vez en Zaragoza en 1567, en la cual nos centraremos a continuación.

\section{GIROLAMO MANFREDI Y SU LIBER DE HOMINE}

El médico, astrólogo y profesor de la Universidad de Bolonia Girolamo Manfredi ${ }^{89}$ procedía de una familia de origen humilde, en cuyo seno se habían dado médicos activos en Bolonia desde el siglo XIII. Nacido hacia 1430 y muerto a finales del verano de 1493, Manfredi alcanzó riqueza y fama en su ciudad natal, entonces uno de los principales centros universitarios de Occidente, gobernada por Giovanni II Bentivoglio, bajo cuya protección siempre se mantuvo.

Como pauper studens, Girolamo inició en Bolonia ${ }^{90}$ sus estudios de artes

llevadas a cabo a partir del texto latino, la de Zaragoza de 1494 y otra impresa en Burgos en 1495 con el título de Epílogo en medicina y cirurgia. El Fasciculus medicinae circuló por Alemania en tradición manuscrita y de forma anónima. Cuando el texto pasó a Italia y se imprimió, se consideró que el médico alemán Johannes de Ketham, posesor de un manuscrito en el cual escribió su nombre, era el autor de aquellos materiales. Sobre esta obra y su autoría, véase especialmente Pesenti, T., ed. (2001), Il 'Fasciculus medicinae' ovvero le metamorfosi del libro umanistico, 2 vols., Padua, Università degli Studi di Padova.

88 Herrera, Ma.T., ed. (1990), Johannes de Ketham, Compendio de la humana salud, Madrid, Arco/Libros. El capítulo al que nos referimos es el titulado «De algunas cuestiones de los miembros generativos y de los secretos de las mujeres» (pp. 118-161). GARCÍA BALLESTER (2001), pp. 347-350, analiza la traducción castellana y señala la relación del capítulo citado con la tradición aristotélica de los problemata. PESENTI (2001), vol. 1, pp. 37-38, apunta la relación del texto con el Omnes homines.

89 Sobre Girolamo Manfredi, véase Thorndike, L. (1923-1958), A History of Magic and Experimental Science, 8 vols., Nueva York, Columbia University Press-Londres, Macmillan, vol. 2 (1934), pp. 458-465; Trombetti Budriesi, A.L., Foresti, F., y NAdA Patrone, A.M., eds. (1988), Girolamo Manfredi, Liber de homine: Il Perché, Bolonia, Luigi Parma.

90 Trombetti Budriesi, A.L. (1990), «Un giurista e un astrologo: Andrea Barbazza e Girolamo Manfredi. Qualque divagazione sull'insegnamento universitario a Bologna nel secondo Quattrocento», en CAPITANI, O., ed., Cultura universitaria e pubblici poteri a Bologna dal XII al XV secolo: Atti del 2. Convegno (Bologna, 20-21 maggio 1988), Bolonia, 
- paso previo obligatorio para acceder a la facultad de medicina-, aunque se doctoró en Ferrara en 1455. Pocos años después, en 1459, recibía la tonsura eclesiástica. Desde 1455, Manfredi fue lector de lógica y de filosofía en el Estudio de Bolonia. Tras doctorarse en medicina en Parma en 1466, se desplazó a Bolonia, en cuya universidad leyó medicina y astrología hasta su muerte.

Sabemos que practicó la medicina, pues él mismo explica que asistió a enfermos de peste. Pero su prestigio profesional y social lo adquirió, sobre todo, a partir de la práctica de la astrología, que le proporcionó una altísima reputación. Desde el curso 1476-1477, la Universidad de Bolonia le encargó que, además de las clases, faciat iudicium et tacuinum cada año. En vida fue considerado el mejor de los astrólogos de Italia, y príncipes y ciudades se disputaron sus servicios. Se le encargaron tareas delicadas, como por ejemplo la elección del momento más favorable para que las naves de la cruzada contra los turcos, promovida por el papa Pío II en 1464, se hicieran a la mar desde Ancona — cruzada que quedó interrumpida bruscamente con la muerte del pontífice. A veces, sus predicciones provocaron incidentes y polémicas, como la cólera en que montó Galeazzo Maria Sforza por una predicción nada favorable, o las discusiones que mantuvo con Giovanni Pico della Mirandola. Estos conflictos fueron, posiblemente, la causa del alejamiento temporal de Manfredi de la cátedra de astrología de Bolonia durante el trienio de 1483-1486, período en que, sin embargo, continuó impartiendo medicina en la misma universidad.

Era ya un hombre de éxito cuando en 1486 se casó con Anna Fontana, descendiente de una conspícua família de Módena, con quien tuvo tres hijos. Efectivamente, Manfredi se convirtió en un hombre de sólida posición económica. Como se desprende de su testamento, que redactó al predecir su propia muerte, tenía casa en Bolonia, dos más fuera de la ciudad, una biblioteca con un centenar de libros (entre los cuales 40 de medicina y filosofía, 17 de astrología y 14 de poesía) y otros bienes. En sus últimas voluntades dispuso asimismo que su entierro se realizara a la luz de las estrellas y en la intimidad, evitando así la pompa que hubiera sido previsible en un personaje de una biografía como la suya.

Manfredi fue autor de diversas obras, principalmente médicas y astrológicas, que se beneficiaron de las posibilidades de difusión que brindaba el nuevo invento de la imprenta. En primer lugar, la que tituló Liber de homine, un tratado de divulgación médica que, precisamente por esta razón, escribió en

Comune di Bologna (Istituto de Storia), pp. 197-223, relaciona los dos personajes a partir de un incidente provocado por un pronóstico astrológico para el año 1477 y los circunscribe en el marco universitario de la ciudad de Bolonia. 
italiano, y que constituye una de las primeras obras de medicina que se imprimieron en Bolonia (1474) ${ }^{91}$. Esta obra se imprimió después en Nápoles en $1478^{92}$ y de nuevo en Bolonia en $1497^{93}$. Como veremos más adelante, hasta la segunda mitad del siglo XVII se imprimieron en distintos lugares de Italia dos decenas de ediciones más de esta obra.

Pocos años más tarde encontramos a Manfredi actuando como curador, junto con Galeotto Marzio, Cola Montano y Pietro Bono Avogaro, de la edición de Bolonia (pretendidamente de 1462, en realidad de 1477) de la Geographia de Ptolomeo, la primera de esta obra que incluyó mapas ${ }^{94}$. A continuación, Manfredi volvió a la lengua vulgar para escribir dos tratados médicos, el Trattato della pestilenza (Bolonia, 1478), que se imprimió después en latín (Bolonia, ca. 1482) ${ }^{95}$, y una Anathomia $(1490)^{96}$. Sus pronósti-

91 Lo fue por Ugo Ruggieri y Domenico Bertocchi, que habían iniciado un año atrás su trabajo editorial. Se puede consultar en Hellinga, L., dir. (1992-), Incunabula: The Printing Revolution in Europe, 1455-1500. Full-text Incunabula on Microfiche, Woodbridge [etc.], Research Publications, Unit 15, MI 31. Esta es la edición que se transcribe en TROMBETTI BUDRIESI, FORESTI y NADA PATRONE (1988), volumen de gran formato con numerosas ilustraciones que se publicó con motivo de la celebración del noveno centenario de la fundación de la Universidad de Bolonia. Contiene flagrantes errores de transcripción, como la omisión de alguna pregunta (I.III.11) o de fragmentos enteros (I.IV.13; I.IV.57), así como olvidos de magnitud considerable, como el de la edición de Nápoles de 1478, que no se cita.

92 Impresión efectuada por Francesco del Tuppo. HellingA (1992-), Unit 13, MI 95.

93 Reimpresión de la edición de 1474 llevada a cabo por Ugo Ruggieri.

94 KLEBS, A.C. (1938), «Incunabula Scientifica et Medica: Short Title List», Osiris, 4, 1359 [reed. anast. (1963): Hildesheim, Georg Olms], § 812.2; STILLWELl, M.B. (1970), The Awakening Interest in Science During the First Century of Printing (1450-1550): An Annotated Cheklist of First Editions Viewed From the Angle of Their Subject Content (Astronomy Mathematics - Medicine - Natural Science - Physics - Technology). Nueva York, The Bibliographical Society of America, § 212. Véase una reproducción en HELLINGA (1992-), Unit 3, ip 01082000. Galeotto Marzio fue autor de un De homine estampado en Bolonia en 1471 (HellingA, 1992-, Unit 13, MI 46), una farragosa suma de adivinación para la metoposcopia, la fisiognomía y la quiromancia que Manfredi conoció sin lugar a dudas; en 1477, Marzio fue acusado de herejía por su De incognitis vulgo (TROMBETTI BUDRIESI, ForeSTI y NADA PATRONE, 1988, p. 17).

95 Klebs (1938), § 655-656; STILlWell (1970), § 447. Se puede consultar la edición de 1478 en Hellinga (1992-), Unit 15, MI 32.

96 Esta obra, omitida en los repertorios de incunables científicos, fue editada parcialmente por Singer, Ch.J. (1917), A Study in Early Renaissance Anatomy, With a New Text: The 'Anathomia' of Hieronymo Manfredi (1490), Transcribed and Translated by A. Mildred Westland, Oxford, Clarendon Press (Studies in the History and Method of Science, 1), pp. 79-164. 
cos astrológicos anuales ${ }^{97}$ fueron reiteradamente impresos (desde 1475 hasta el siglo XVII) en Bolonia y otros lugares, tanto en latín (Ephemerides astrologicae operationes medicas expectantes) como en italiano ${ }^{98}$. Fue autor también de una colección de aforismos astrológicos titulada Centiloquium de medicis et infirmis (Bolonia, 1483 y 1489; Venecia, 1500; Nuremberg, $1530)^{99}$. A todo esto hay que añadir un comentario perdido al Quadripartitum de Ptolomeo, que Manfredi cita en su Trattato della pestilenza ${ }^{100}$.

Su Liber de homine o Il Perché101, la obra que ahora nos interesa, se divide en dos libros. El primero, dedicado a la conservación de la salud ${ }^{102}$, es un régimen de sanidad que consta de siete capítulos, en los cuales se tratan las seis 'cosas no naturales' del galenismo. Así, el primer capítulo está dedicado a la comida, el segundo a la bebida, el tercero al sueño y la vigilia, el cuarto al ejercicio físico, el quinto a la evacuación y repleción (donde se consideran los eméticos y purgantes, la orina, las heces, el sudor, los flujos humorales, la menstruación, el semen y el coito), el sexto al aire que nos rodea y el séptimo y último a las pasiones del alma ${ }^{103}$. El primero de los siete capítulos, el dedicado a la alimentación, es interrumpido después de la pregunta 59 por un largo fragmento en versos decasílabos que ocupan 19 folios, en los cuales se toman en consideración diversos tipos de carne, vegetales, panes, vísceras de animales, peces, aves, frutas, hierbas aromáticas, especias orientales y bebi-

97 Véase Serra ZanetTi, A. (1952), «I pronostici di Girolamo Manfredi», en Studi riminesi e bibliografici in onore di Carlo Lucchesi, Faenza, Tip. F.lli Lega, pp. 193-213; y TromBETTI BUDRIESI (1990).

98 KLEBS (1938), § 654.

99 KLEBS (1938), § 657 y 826.3 (ediciones de 1489 y 1500). La edición de 1483 en Hellinga (1992-), Unit 15, MI 30.

100 En el capítulo 46. Véase Trombetti Budriesi, Foresti y Nada Patrone (1988), p. 21, nota 5. Constan también dos obras más: unos versos latinos de temática astrológica y un breve tratado astrológico (Eiusdem Manfredi embolismarum ratio), que, en realidad, deben atribuirse a otros dos astrólogos homónimos y que vivieron en la Bolonia de su tiempo (THORNDIKE, 1923-1958, vol. 4, p. 461).

101 LAWN (1963), pp. 110-112, considera esta colección de problemas junto con las francesas escritas en forma dialogada de finales del siglo XIII, el Livre de Sidrach y el Dialogue de Placides et Timéo o Le livre des secrets aux philosophes, y la italiana L'acerba de Cecco d'Ascoli (m. 1327).

102 La tabla de la edición de 1474, escrita en latín, empieza así: «Liber De Homine: cuius sunt libri duo. Primus liber de conseruatione sanitatis» (f. 2). Véase HeLlingA (1992-), Unit 15, MI 31.

103 En la ordenación de las seis 'cosas no naturales', Manfredi (como hacen también otros regímenes de sanidad) no sigue el orden canónico establecido por la Isagoge y el Pantegni. Véase al respecto el estudio introductorio de Gil SoTRES (1996), pp. 38, 62, 72, 89 y 91, que proporciona ejemplos de lo que decimos. 
das (el vino, la cerveza, el agua, la leche). No hemos podido identificar este fragmento ${ }^{104}$, que sigue las pautas de los tacuina sanitatis de los siglos precedentes ${ }^{105}$ y de los conceptos del Regimen sanitatis de la llamada Escuela de Salerno ${ }^{106}$ y que no se aleja de los capítulos que dedican los regímenes de sanidad a los alimentos clásicos.

El segundo libro del Liber de homine, que estudia las cosas relacionadas con la composición del hombre ${ }^{107}$, es un tratado de fisiognomía ${ }^{108}$ en trece capítulos que plantea cuestiones relacionadas con los pelos (1), la cabeza (2), los ojos (3), la boca (4), las orejas (5), la nariz (6), las manos y los brazos (7), los pies (8), el cuello y la espalda (9), la voz (10), los órganos internos (11), el estómago, la sed y el hambre (12) y los miembros de la generación (13).

En total son 568 preguntas y respuestas de raigambre aristotélica que Man-

104 En general, se explican brevemente las características del alimento en cuestión, sus virtudes alimenticias y terapéuticas y, finalmente, a qué tipo de complexión resulta más útil su consumo.

105 Sobre estos manuales de higiene traducidos del árabe al latín durante el siglo XII y de notable éxito posterior, véase DeLISLE, L. (1896), «Traités d'hygiène du Moyen Âge», Journal des savants, pp. 518-540 [reseña de Tacuinum sanitatis in medicina: Ein veronesisches Bilderbuch und die höfische Kunst des XIV. Jahrhunderts, ed. Von SCHLOSSER, J., 1895, Viena]; UnTERKIRChER, F., y TAlBOT, Ch.H., eds. (1967), Tacuinum sanitatis in medicina: Codex Vindobonensis series nova 2644 der Österreichischen Nationalbibliothek, 2 vols., Graz, Akademische Druck u. Verlagsanstalt; Cogliati ARAnO, L., ed. (1973), Tacuinum sanitatis, Milán, Electa; GArcía BALlester, L., ed. (1974), Códice C-67 de la Biblioteca Universitaria de Granada, Granada, Universidad de Granada.

106 Véase estos textos, que se difundieron desde finales del siglo XIII, en DE RENZI, S., ed. (1852-1859), Collectio Salernitana, 5 vols., Nápoles, Tip. del Filiatre-Sebezio [reimpr. (1967) Bolonia, Forni], vol. 1.

107 «Liber secundus de causis in homine circa compositione eius» (f. 8), en HellingA (1992-),Unit 15, MI 31.

108 Sobre fisiognomía en general se pueden consultar Evans, E.C. (1969), Physiognomics in the ancient world, Filadelfia, American Philosophical Society (Transactions of the American Philosophical Society, 59, part 5); CARO BAROJA, J. (1988), Historia de la fisiognómica: el rostro y el carácter, Madrid, Istmo; AGRIMI, J. (2002), Ingeniosa Scientia Nature: Studi sulla fisiognomica medievale, Florencia, SISMEL-Edizioni del Galluzzo. Sobre los tratados fisiognómicos atribuidos a Aristóteles, véase Martínez Manzano, T.Ma', y CAlvo DelcaN, C., trad. (1999), Pseudo Aristóteles, Fisiognomía, y Anónimo, Fisiólogo, Madrid, Gredos; CuRrIe, H.McL. (1985), «Aristotle and Quintilian: Physiognomical Reflections», en GoTTHELF, A., ed., Aristotle on Nature and Living Things: Philosophical and Historical Studies Presented to David M. Balme on His $70^{\text {th }}$ Birthday, Pittsburgh, Mathesis-Bristol, Bristol Classical Press, pp. 359-366. Sobre las Quaestiones basadas en el tratado de fisiognomía pseudo-aristotélico que escribió Jean Buridan, rector de la Universitad de París y uno de los comentaristas más importantes de Aristóteles en el siglo XIV, véase THORNDIKE, L. (1943), «Buridan's Questions on the Physiognomy Ascribed to Aristotle», Speculum, 18, 99-103, que estudia los tres manuscritos que se conocen de la obra de Buridan y cita otros comentaristas. 
fredi dispuso ${ }^{109}$ siguiendo el sistema de expresión práctica de la ciencia y la didáctica escolásticas habitual en los siglos XIV y XV, del que se sirvió con fortuna para redactar este escrito enciclopédico de carácter divulgativo. Para construir su obra, Manfredi partió, pues, de un género de larga tradición. Pero hay que subrayar que tuvo la idea de agrupar en un solo volumen un régimen de sanidad y un tratado de fisognomía, idea que no recoge del género de los problemas sino que pudo haberla sacado del divulgadísimo Régime du corps que Aldobrandino de Siena escribió en francés hacia la mitad del siglo XIII o de alguna versión del Secretum secretorum pseudo-aristotélico ${ }^{110}$.

\section{EL ÉXITO DEL LIBER DE HOMINE: LAS EDICIONES ITALIANAS Y LAS TRADUC- CIONES CATALANA Y CASTELLANA}

Situándonos en un ámbito estrictamente italiano, podemos considerar dos testimonios de la difusión de la obra de Girolamo Manfredi, siempre entre un público no especialista. Por un lado, sabemos que la parte fisiognómica del Liber de homine constituyó una de las fuentes del pensamiento (anatómico) de Leonardo da Vinci111. Por otro, conocemos la existencia de numerosas ediciones de la obra, que se llevaron a cabo en los siglos XV, XVI y XVII. Más allá del ámbito italiano, las traducciones hasta ahora identificadas constituyen otro importante testimonio de su aceptación y difusión.

Liber de homine o Il Perché es el título con el que se imprimió la obra de Manfredi en tres ocasiones, como se ha visto antes, en la Italia del siglo $\mathrm{XV}^{112}$.

109 Manfredi parte de los Problemas pseudo-aristotélicos, texto al que clasifica, selecciona, amplía, mezcla, elimina preguntas y añade otras nuevas. Para la relación entre la obra de Manfredi y la tradición textual del género de los problemas, véase CARRÉ y CIFUENTES (en prensa). También CARRÉ, A. ed. (2004), Girolamo Manfredi, Quesits o perquens: regiment de sanitat i tractat de fisiognomonia, Barcelona, Barcino, 2004.

110 En su régimen de salud, Aldobrandino de Siena incorpora un apartado de fisiognomía. La versión breve del Secretum secretorum fusiona las dos disciplinas en un solo capítulo, como ocurre en la traducción castellana Poridat de las poridades. Conocemos la existencia de un manuscrito italiano del Secretum secretorum que contiene exclusivamente estas dos materias. Lo estudiamos con más detalle en nuestros trabajos citados en la nota anterior, esp. en CARRÉ (2004), pp. 37-40, con abundante bibliografía.

111 Véase LaUrenZA, D. (1998), «La ‘composizione’ del corpo: fisiognomica ed embriologia in Leonardo», Nuncius, 13, 3-37, en part. pp. 13-20; y LAURENZA, D. (1997), «Il pensiero medico di Leonardo intorno al 1490: Hieronymo Manfredi e altre probabili fonti», Achademia Leonardi Vinci, 10, 60-75.

112 GaleaZZI, O., y ZigiotTI, G.L. (1989), «Due cinquecentine del 'Libro del perché': annotazioni su un itinerario culturale», Medicina nei Secoli: Arte e Scienza, 1, 49-63, citan una edición 
Las veintitrés ediciones italianas restantes, que llevan títulos algo diferentes, las podemos clasificar en dos grupos, como muestra la tabla siguiente ${ }^{113}$ :

\begin{tabular}{|c|l|}
\hline A. Reimpresiones del siglo XVI & \multicolumn{1}{|c|}{$\begin{array}{c}\text { B. Ediciones manipuladas de } \\
\text { los siglos XVI y XVII }\end{array}$} \\
\hline $\begin{array}{l}\text { Opera nova intitulata Il Perché, utilis- } \\
\text { sima ad intendere la cagione de molte } \\
\text { cose \& maximamente alla conservatio- }\end{array}$ & $\begin{array}{l}\text { Libro intitulato Il Perché, tradotto di latino in } \\
\text { italiano dell' eccellente Medico \& astrologo } \\
\text { ne della sanità. Novamente stampada } \\
\text { (Venecia } 1507,1512,15141^{114}, 1520^{115},\end{array}$ \\
$\begin{array}{l}\text { assai luoghi dilucidato \& illustrato. Con } \\
\text { mostrar le cagioni d'infinite cose, appartenenti }\end{array}$ \\
\hline $523,1524,1525^{116}, 1532,1536^{117}$, & alla sanità: con la dichiaratione delle virtù \\
\hline
\end{tabular}

impresa en Bolonia en 1473 que no hemos podido documentar en ninguna otra parte. No aparece en VALEZIANI, E., y CERULli, E. (1965), Indice generale degli incunaboli delle biblioteche d'Italia, vol. 4, Roma, Istituto Poligrafico dello Stato-Libreria dello Stato, pp. 32-33, § 6110-6119.

113 Hemos consultado los catálogos informatizados de la British Library (http://blpc.bl.uk/), el índice del Istituto centrale per il catalogo unico (ICCU) italiano (http://www.iccu.sbn.it/), el Catalogue collectif de France (http://www.ccfr.bnf.fr/) y el Catálogo colectivo del patrimonio bibliográfico español (http://www.mcu.es/gni-bin/ccpb/).

114 Edición citada sólo por GALEAZZI y ZIGIOTTI (1989), que no aparece documentada en NoRTON, F.J. (1958), Italian printers, 1501-1520, Londres, Bowes \& Bowes. Hemos tenido acceso al ejemplar conservado en la biblioteca de la Universidad de Valencia. Se trata de una miscelánea que contiene las Opere dello elegante poeta Seraphino Aquilano (Venecia, 1507), el Libro del homo in lingua materna, compilato per misser Hieronymo di Manfredi da Bologna ad utilità et delectatione del genere humano, inelqual dilucida le cause della natura circa la conservatione dela sanità et dele cose se sumeno in cibo et poto, con la compositinoe del homo per la quale se cognosce naturalmente le bontà et defecti di quello, ditto vulgarmente Perché (Venecia, Simon de Luere, 1514) y, finalmente, las Opere de misser Antonio Thibaldo da Ferrara (Venecia, 1514). Después del título de la obra de Manfredi hay una figura humana masculina, con líneas que señalan distintas partes de la anatomía. En el colofón, encima del nombre del impresor, aparece escrito a mano el precio del libro, que se compró en Bolonia poco después de ser impreso («Costà lo present libre en Bolonia VII iugacello, a 16 de febrer de 1515?»). Agradecemos a Rosanna Cantavella que nos haya facilitado estas informaciones.

115 Algunas ediciones presentan títulos algo diferentes, como ésta de 1520: Opera nova intitulata Il Perché, utilissima ad intendere la cagione de molte cose \& maximamente alla conservatione della sanità e phisonomia et virtù delle herbe. Novamente stampada. Hemos consultado el ejemplar de la biblioteca del Institut Botànic de Barcelona, 0203 C/II/2.

116 Edición citada sólo por GALEAZZI y ZiGIOTTI (1989), que no recogen las de Venecia 1524, 1532, 1536 y 1540. Podría tratarse, simplemente, de un error de transcripción de ambos autores.

117 En el título se lee 1536. En el colofón, 1526. 


\begin{tabular}{|c|l|}
\hline A. Reimpresiones del siglo XVI & \multicolumn{1}{|c|}{$\begin{array}{c}\text { B. Ediciones manipuladas de } \\
\text { los siglos XVI y XVII }\end{array}$} \\
\hline $1540,1567^{118}$; Ancona $\left.1512^{119}, 1514\right)$ & $\begin{array}{l}\text { d'alcune herbe. Opera utilissima è necessariis- } \\
\text { sima, \& di nuovo ristampata e rispurgata da } \\
\text { quelle cose, che havessero potuto offendere il }\end{array}$ \\
& $\begin{array}{l}\text { simplice animo del lettore (Venecia 1588, } \\
1591^{120}, 1591^{121}, 1596,1600,1607,1613,1622, \\
\left.1629,1678^{122} \text {; Padua } 1668\right)\end{array}$ \\
\hline
\end{tabular}

Las pertenecientes al bloque A son ediciones que constan de un proemio en latín donde se menciona a Girolamo Manfredi como autor de la obra, que se afirma traducida del latín al italiano. Sigue la tabla con los títulos de los capítulos y las preguntas que contiene cada uno de ellos. El primer libro contiene siete capítulos y el segundo trece. En total, tenemos 568 preguntas con sus respuestas que aparecen en el texto una detrás de otra, sin divisiones de ningún tipo. Todas estas ediciones son reimpresiones, con el proemio incluido, de la primera edición de la obra (Bolonia, 1474) ${ }^{123}$.

Las ediciones del bloque $\mathrm{B}$ se caracterizan por las manipulaciones a que ha sido sometido el texto de Manfredi. Son ediciones prácticamente idénticas

118 Esta edición, que sólo hemos encontrado documentada en el índice del ICCU, lleva por título Opera nova intitulata Il Perché, utilissima ad intendere la cagione di molte cose \& massimamente alla conservatione della sanità \& phisonomia et virtù delle herbe. Novamente emendata, et purgata de gli errori inumerabili, et nel primo esser suo ridutta et riformata. Hemos visto el ejemplar que se encuentra en la Biblioteca de la Facoltà di Lettere e Giurisprudenza de la Università degli Studi di Milano, Alf. Ant. V. 28.

119 Se trata de la primera obra impresa en Ancona, por Bernardino Oliva. Edición citada sólo por GALEAZZI y ZIGIOTTI (1989), que aparece documentada en NORTON (1958), p. 2.

120 Impresa por Giovanni Battista Bonfandino. Ejemplar en la Biblioteca de la Universitat de Barcelona, 0703 XVI-1233.

121 Impresa por Giovanni Fiorina. Ejemplar en Madrid, BN, 2-56619.

122 Esta edición veneciana y la paduana consignada a continuación tienen un título algo distinto: Il novo lume dell'arte overo Il Perche, opera copiosa di varie cognitioni, cioè osservation per la sanità, qualità de cibi, virtú dell'herbe, fisonomia, secreti mirabili, qualità de l'arie, paesi e città, et altre, etc. Dell' Eccll. Medico \& astrologo il sig. Gieronimo de Manfredi. Ejemplar de la edición de 1678 en Madrid, BN, 3-5546.

123 Lo hemos comprobado en las ediciones de Ancona 1514 y Venecia 1523, 1532 y 1536 que se encuentran en la British Library de Londres (agradecemos a Carmen Caballero la consulta de estos ejemplares); en las de Venecia 1507, 1524 y 1540 de la Bibliothèque Nationale de France de París (nuestro agradecimiento esta vez a Lola Badia); en el ejemplar de la edición de Venecia 1520 que se encuentra en la Biblioteca de l'Institut Botànic de Barcelona; y en el citado ejemplar milanés de la edición de Venecia de 1567. 
entre sí, con apenas alguna variante poco significativa. La primera de ellas, impresa por Ventura Salvador, se inicia con un prólogo del impresor dirigido a los lectores donde se explica que la obra es del príncipe de los filósofos, Aristóteles, y que el impresor ha decidido reeditarla porque se trata de una obra importante que da razón de muchas cuestiones. Se justifican así las manipulaciones a que ha sido sometido el texto:

Et essendo opera composta da un Gentile privo del lume della vera fede, l'ho data à ripurgare à persone dottissime, $\&$ catolichissime, le quali le hanno restituito veramente (per dir cosí) la sanità. La onde per lo adietro potrà esser fidelmente letto da tutti, senza alcuna sorte di scropolo... ${ }^{124}$

Efectivamente, esta edición contiene 110 preguntas menos que las del primer grupo, supresiones que obedecen a razones ideológicas, producto de la Contrarreforma, que dejó sentir de este modo su influencia en el contenido de la obra ${ }^{125}$.

En la tabla (que en unas ediciones figura al principio y en otras al final del texto) se expone que la obra está dividida en ocho partes y se enumeran los capítulos de cada una de ellas, con su correspondiente título ${ }^{126}$. Las seis primeras partes corresponden al régimen de sanidad y las dos restantes al tratado de fisiognomía. Las ocho partes están explicitadas también en el texto. Este segundo grupo de ediciones contiene el habitual fragmento en verso en la primera parte y una xilografía con las distintas partes del cuerpo humano en la cuarta, que justifica el adjetivo «illustrato» del título ${ }^{127}$. Después del último porqué, hay un fragmento que no aparece en las ediciones del primer grupo y que lleva por título «Unguento da viso qual usava la Regina de Ungaria, cosa eccellente».

Tal como se ha apuntado antes, conocemos también la existencia de dos traducciones a otras tantas lenguas románicas del Liber de homine o Il Perché,

124 Citamos a partir de Trombetti Budriesi, Foresti y NADA Patrone (1988), p. 17.

125 Se han suprimido 18 preguntas sobre cuestiones sexuales, 82 de fisiognomía y quiromancia, y 10 más sobre temas diversos. Véase GALEAZZi y ZiGiotTi (1989), donde se comparan las ediciones de Ancona 1512 y Venecia 1588.

126 Después empieza propiamente el texto: «Opera intitulata il Perché, utilissima ad intendere le cagione de molte cose, \& massimamente alla conservatione della sanità, \& cognitione delle virtù dell'herbe». Citamos a partir del ejemplar de 1588 conservado en Madrid, BN, 3-52268.

127 La xilografía se encuentra en la edición de 1588 (ejemplar en Madrid, BN, 3-52268, f. 159) y en la de 1591 impresa por Giovanni Battista Bonfandino (ejemplar en la Biblioteca de la Universitat de Barcelona, 0703 XVI-1233, f. 160). En la edición de 1600 es una pequeña cabeza humana (ejemplar en Madrid, BN, 3-27691, f. 160). La edición de 1591, impresa por Giovanni Fiorina, no tiene la xilografía. 
ambas realizadas en el ámbito ibérico. En 1499 Pere Posa imprimió en Barcelona una traducción catalana anónima de la obra de Girolamo Manfredi con el título de Quesits, aunque atribuyéndola a Alberto Magno. Esta última circunstancia, que se explica por haberse efectuado la traducción a partir de la edición de Nápoles de 1478 -impresa por Francesco del Tuppo- en la que se realiza idéntica atribución, ha conllevado que la obra impresa por Posa no haya sido identificada correctamente hasta hace poco. La publicación previa de otros trabajos nuestros sobre esta traducción catalana ${ }^{128}$ nos permite evitar extendernos más sobre ella y centrarnos a continuación en la traducción castellana.

La traducción castellana de esta obra de Manfredi, realizada por Pedro de Ribas, ${ }^{129}$ eclesiástico aragonés que fue vicario de la parroquia de San Nicolás de Bari de Zaragoza desde 1575, lleva por título Libro llamado El Porqué, provechosíssimo para la conservación de la salud y para conocer la phisonomía y las virtudes de las yerbas. Se imprimió por primera vez en Zaragoza en 1567, a instancias del impresor y librero Antonio de Furno ${ }^{130}$ que la mandó traducir, y nos constan documentadas otras cuatro ediciones más de esta traducción, publicadas todas ellas en el siglo XVI. Son volúmenes en octavo que contienen el texto de Girolamo Manfredi aunque sin mencionar nunca su nombre. ${ }^{131}$ El texto aparece precedido de una dedicatoria a Fernando de Ara-

128 Véase CARré, A., y Cifuentes, Ll. (2001), «Quesits (Barcelona, Pere Posa, 1499): una traducció catalana desconeguda del Liber de homine (Il Perché) de Girolamo Manfredi amb filtre napolità», Arxiu de Textos Catalans Antics, 20, 543-60; y CARRÉ (2004).

129 Hay pocos datos sobre el personaje. Véase LATASSA Y ORTín, F. (1798-1802), Biblioteca nueva de los escritores aragoneses que florecieron desde el año 1500 hasta 1802, 6 vols., Pamplona, J. de Domingo [ed. electrónica de Pedraza Gracia, M.J., SÁnchez IBÁÑEz, J.A., y Julve LARRAZ, L., 1999, Zaragoza, Universidad de Zaragoza, http://fyl.unizar.es/latassa/Latassa obra.html], vol. 1, p. 319. Véase también Gran Enciclopedia Aragonesa (1980-1982), 10 vols., Zaragoza, Unión Aragonesa del Libro, s.v. «Rivas, Pedro de», artículo firmado por BALLESTER, R.

130 Sobre Antonio de Furno, véase Herrero Mediavilla, V., ed. (2000), Archivo biográfico de España, Portugal e Iberoamérica, $3^{\mathrm{a}}$ ed. revisada y aumentada, Munich, K.G. Saur, vol. 5, s. v. «Furno, Antonio de (c. 1567), impresor, librero», voz firmada por HAEBLER, K., que obtiene su información de la edición de 1567, reproducida en HeLLINGA (1992-), MI I 355-287.

131 Tampoco lo recoge el bibliógrafo sevillano ANTONIO, N. (1672), Bibliotheca Hispana Nova..., 2 vols., Roma, ex officina Nicolai Angeli Tinassii [reed. corr. (1783 y 1788), Madrid, Vda. de Joaquín Ibarra; reimpr. facs. (1996), Madrid, Visor]; véase vol. 2, p. 231: «Petrus de Ribas, vicarius ecclesiae S. Nicolai urbis Caesaraugustanae, dedit ex sermone Italiae vernaculo: El Porque: sive librum huius nuncupationis. Matriti apud Petrum de Madrigal 1598. in $8^{\circ}$. quem ait utilissimum esse ad sanitatem tuendam, \& physiognomicam artem, simulque naturae omnium herbarum cognitionem, ad D. Ferdinandum de Aragonia, Caesaraugustanum antistitem, directum». PÉREZ PASTOR, C. (1891-1907), Bibliografia madrileña o descripción de las 
gón (1498-1575), nieto de Fernando el Católico y arzobispo de Zaragoza, además de cartas y prólogos distintos según las ediciones, como veremos. Aunque el título hace pensar en tres grandes apartados, contiene las preguntas de la obra original italiana sin divisiones en libros ni en capítulos. Efectivamente, como en las ediciones italianas, las preguntas del régimen de sanidad preceden a las del tratado de fisiognomía; sin embargo, el fragmento en verso sobre las «virtudes de las yerbas», que interrumpe el primer capítulo de la primera parte del original italiano, aparece al final de la traducción castellana, como un apartado independiente ${ }^{132}$. Cierra estos volúmenes un índice temático ordenado por a, b, c, que ocupa doce folios.

La tabla siguiente muestra las cinco ediciones localizadas de la traducción de Pedro de Ribas, que hemos consultado en su totalidad ${ }^{133}$ :

\begin{tabular}{|c|l|l|l|l|}
\hline $\begin{array}{c}\text { Núm. } \\
\text { edición }\end{array}$ & $\begin{array}{c}\text { Ciudad y } \\
\text { fecha }\end{array}$ & \multicolumn{1}{|c|}{ Título } & \multicolumn{1}{c|}{ Impresor } & $\begin{array}{c}\text { Ejemplares } \\
\text { conservados }\end{array}$ \\
\hline 1 & $\begin{array}{l}\text { Zaragoza, } \\
1567^{134}\end{array}$ & $\begin{array}{l}\text { Libro llamado El Porqué, } \\
\text { provechosíssimo para la }\end{array}$ & $\begin{array}{l}\text { Juan Millán } \\
\text { «Se vende en }\end{array}$ & $\begin{array}{l}\text { Madrid, BN, R } \\
8299, \mathrm{R} 14323,\end{array}$ \\
\hline
\end{tabular}

obras impresas en Madrid, 3 vols., Madrid, Tip. de los Huérfanos [reimpr. (1970-1971), Amsterdam, Gérard Th. van Heusden], vol. 1 (Siglo XVI: de 1556 al 1600), § 595, que da cuenta de la edición de Madrid 1598, impresa por Pedro Madrigal a costa de Miguel Martínez, apunta que la obra italiana Il Perché es de «Jerónimo Manfredi» y da como referencia la biblioteca de D. José Sancho Rayón. Sobre el bibliófilo José Sancho Rayón (1830-1900) y sus prácticas poco escrupulosas (que le llevaron a falsificar colofones), véase SÁNCHEZ MARIANA, M. (1993), Bibliófilos españoles, desde sus orígenes hasta los albores del siglo XX, Madrid, Biblioteca Nacional-Ministerio de Cultura-Ollero \& Ramos, pp. 85-87.

132 Hay que señalar que este largo fragmento es omitido por completo en la traducción catalana de 1499.

133 Véase SAlvá MallÉn (1872), vol. 2, § 2741; LATASSA Y ORTín, F. (1798-1802), s. v. «Ribas, D. Pedro de»; Picatoste Rodríguez (1891), § 949; LóPez PiÑERO, J.Mª., et al. (1987-1996), Bibliographia medica hispanica, 1475-1950, 7 vols. publ., Valencia, Universitat de València-CSIC, Instituto de Estudios Documentales e Históricos sobre la Ciencia, § 339344; y LÓPEZ PIÑERO, J.Ma., et al. (1981-1986), § 954-959.

134 Sobre la imprenta en Zaragoza, una de las primeras ciudades hispánicas en utilizar el invento, véase RuIZ LaSAla, I. (1975), Historia de la imprenta en Zaragoza, con noticias de las de Barcelona, Valencia y Segovia, Zaragoza, Gráf. San Francisco.

135 Esta primera edición contiene una «epístola» de Antonio de Furno a Fernando de Aragón, una «nota» de Antonio de Furno al lector, un «proemio» de Pedro de Ribas y el «compendio y sumario», que transcribimos en el Apéndice I. Aunque no hemos encontrado más datos sobre el mercader de libros, su apellido parece indicar un origen italiano. 


\begin{tabular}{|c|c|c|c|c|}
\hline & & $\begin{array}{l}\text { conservación de la saludy } \\
\text { para conocer la phisono- } \\
\text { mía y las virtudes de las } \\
\text { yerbas. Traduzido de tos- } \\
\text { cano en lengua castellana } \\
\text { por Pedro de Ribas }\end{array}$ & $\begin{array}{l}\text { casa de Antonio } \\
\text { de Furno, merca- } \\
\text { der de libros»» }\end{array}$ & R $15341^{135}$ \\
\hline & $\begin{array}{l}\text { Madrid, } \\
1579\end{array}$ & $\begin{array}{l}\text { Libro llamado El Porqué, } \\
\text { provechosíssimo para la } \\
\text { conservación de la saludy } \\
\text { para conocer la phisono- } \\
\text { mía y las virtudes de las } \\
\text { yerbas. Traduzido de tos- } \\
\text { cano en lengua castellana } \\
\text { por Pedro de Ribas }\end{array}$ & $\begin{array}{l}\text { Francisco Sán- } \\
\text { chez / Guillermo } \\
\text { Druy }\end{array}$ & Ninguno ${ }^{136}$ \\
\hline 2 & $\begin{array}{l}\text { Madrid, } \\
1581^{137}\end{array}$ & $\begin{array}{l}\text { El Porqué: libro de proble- } \\
\text { mas en que se da razones } \\
\text { naturales de muchas cosas, } \\
\text { provechosíssimo para con- } \\
\text { servacion de la salud, con } \\
\text { las virtudes y calidades de } \\
\text { algunas yervas. Agora nue- } \\
\text { vamente corregido y enmen- } \\
\text { dado, y en muchos lugares } \\
\text { añadido. Traduzido de tos- } \\
\text { cano en lengua castellana } \\
\text { por Pedro de Ribas }\end{array}$ & $\begin{array}{l}\text { Francisco Sán- } \\
\text { chez }\end{array}$ & $\begin{array}{l}\text { Madrid, } \\
\text { Real Academia } \\
\text { Española, 11- } \\
\text { XI-41138 }\end{array}$ \\
\hline
\end{tabular}

136 Palau Dulcet (1948-1977), vol. 7, p. 553, recoge esta edición y otra con idéntica fecha, pero impresa por Guillermo Drouy; sin embargo, confiesa no haber visto ningún ejemplar ni de una ni de otra. PÉREZ PASTOR (1891-1907), vol. 1, p. 71, § 147-148, contra la opinión de Salvá, quien había afirmado que se trataba de una sola edición, cree que se trata de dos distintas. Por nuestra parte, no hemos localizado esta o estas ediciones en ninguno de los catálogos de bibliotecas que hemos consultado. Véase la nota 133.

137 Edición citada por PÉREZ PASTOR (1891-1907), vol. 1, p. 79, §164.

138 Contiene una «tassa» de Pedro Zapata del Mármol, escribano del Consejo Real (en la que se menciona a Guillermo Druy como impresor del libro), una lista de erratas, la licencia de impresión otorgada a Guillermo Druy con fecha de 1579, una autorización del «doctor Céspedes» (véase la nota 154), fechada también en 1579, una dedicatoria del librero Gaspar de Ortega al licenciado Ruypérez de Ribera, un prólogo de Gaspar de Ortega dirigido «al lector», que habla sólo de una edición anterior a ésta, el «proemio» de Pedro de Ribas y el «compendio y sumario». La puntualización de Gaspar de Ortega respecto a una única edición anterior del libro nos hace sospechar que la supuesta edición de 1579 -de la cual nadie ha visto nunca ejemplar alguno- no existió. Posiblemente, la mención de Guillermo Druy y la fecha de 1579 se refieren a una edición que se debió proyectar pero que no se llevó a cabo, ignoramos por qué razón. Transcribimos los textos en el Apéndice II. 


\begin{tabular}{|c|c|c|c|c|}
\hline 3 & $\begin{array}{l}\text { Alcalá de } \\
\text { Henares, } \\
1587 \\
(1589)^{139}\end{array}$ & $\begin{array}{l}\text { Libro llamado El Porqué, } \\
\text { provechosíssimo para la } \\
\text { conservación de la salud y } \\
\text { para conocer la phisono- } \\
\text { mía y las virtudes de las } \\
\text { yervas. Traduzido de tos- } \\
\text { cano en lengua castellana }\end{array}$ & $\begin{array}{l}\text { Juan Iñíguez de } \\
\text { Lequerica } \\
\text { «A costa de Juan } \\
\text { Sarria, mercader } \\
\text { de libros» (en la } \\
\text { portada) } \\
\text { Hernán Ramírez } \\
\text { «A costa de Joan } \\
\text { García Callejas, } \\
\text { mercader de } \\
\text { libros» (en el } \\
\text { colofón) }\end{array}$ & $\begin{array}{l}\text { Madrid, BN, } \\
12018,{ }^{140} \text { Usoz } \\
10813^{141} \\
\text { Madrid, Real } \\
\text { Academia } \\
\text { Española, } \\
\text { 10-X-71 } \\
\\
\text { Monasterio de } \\
\text { Poblet, R. } \\
\text { 23774143 }\end{array}$ \\
\hline 4 & $\begin{array}{l}\text { Madrid, } \\
1598^{144}\end{array}$ & $\begin{array}{l}\text { Libro llamado El Porqué, } \\
\text { provechosíssimo para la } \\
\text { conservación de la salud y } \\
\text { para conocer la fisonomía } \\
\text { y las virtudes de las yer- } \\
\text { vas. Traduzido de toscano } \\
\text { en lengua castellana }\end{array}$ & $\begin{array}{l}\text { Pedro Madrigal } \\
\text { «A costa de Mi- } \\
\text { guel Martínez» }\end{array}$ & $\begin{array}{l}\text { Madrid, BN, R } \\
18387145\end{array}$ \\
\hline
\end{tabular}

139 Esta edición incluye un colofón fechado en 1589. Véase MARTIN ABAD, J. (1991), La imprenta en Alcalá de Henares (1502-1600), 3 vols., Madrid, Arco/Libros, vol. 3, pp. 140$141, \S 998$, quien, al citar los ejemplares conservados, olvida el de la biblioteca de Poblet.

140 Contiene la licencia real a favor de Francisco Sánchez, librero e impresor, dada en Madrid, 4 de junio de 1579, y firmada por Alonso de Vallejo. Siguen la «epístola» de Antonio de Furno a Fernando de Aragón, el «proemio» de Pedro de Ribas, el «compendio y sumario» y la «nota» de Antonio de Furno dirigida al lector. En el colofón: «Alcalá de Henares, 1589, en casa de Hernán Ramírez, impresor y mercader de libros. A costa de Ioan García Callejas, mercader de libros».

141 Este ejemplar no contiene ni proemio ni dedicatorias. La portada aparece recortada y pegada y en la hoja anterior se lee, a lapiz: «Portada ajena. Falto de ella i ( $\mathrm{sic}$ ) principios. Completo en lo demás». El colofón reza: «Alcalá de Henares, en casa de Hernán Ramírez, impressor y mercader de libros. Año de 1589. A costa de Ioan Garcia Callejas, mercader de libros»».

142 Este ejemplar no contiene portada, por lo que la única fecha que consta es la del colofón, 1589 .

143 Ejemplar idéntico al de Madrid, BN, 12018.

144 Pensamos que ésta, y no la siguiente, es la edición citada por PÉREZ PASTOR (18911907), vol. 1, p. 317, § 596, impresa por Pedro Madrigal a costa de Juan Pérez, mercader de libros.

145 Ejemplar sin portada. Contiene la licencia real, firmada por Alfonso de Vallejo en Madrid el 24 de abril de 1598, una lista de erratas de Juan Vázquez del Mármol, la «epístola» de Antonio de Furno a Fernando de Aragón, el «proemio» de Pedro de Ribas y el «compendio y sumario»». 


\begin{tabular}{|c|l|l|l|l|}
\hline 5 & $\begin{array}{l}\text { Madrid, } \\
1598146\end{array}$ & $\begin{array}{l}\text { Libro llamado El Porqué, } \\
\text { provechosíssimo para la } \\
\text { conservación de la saludy } \\
\text { para conocer la fisonomía } \\
\text { y las virtudes de las yer- } \\
\text { vas. Traduzido de toscano } \\
\text { en lengua castellana }\end{array}$ & $\begin{array}{l}\text { Pedro Madrigal } \\
\text { "A costa de Mi- } \\
\text { guel Martínez» }\end{array}$ & $\begin{array}{l}\text { Barcelona, } \\
\text { Biblioteca de } \\
\text { Catalunya, } \\
\text { Res. } 417-12^{\mathbf{0} 147}\end{array}$ \\
\hline
\end{tabular}

La traducción de Pedro de Ribas no guarda ninguna relación con la traducción catalana anónima, realizada e impresa con bastante anterioridad, a pesar de que ambos traductores efectuaran su tarea en los reinos que formaban la Corona de Aragón. El vicario aragonés explicitó ya en el mismo título que tradujo del italiano («toscano»), hecho que se corrobora en la epístola de Antonio de Furno que figura en la edición de 1567 (véase el Apéndice I). Un estudio detenido de ambas traducciones no deja duda alguna: en primer lugar, en la traducción catalana se atribuye la obra a Alberto Magno, despropósito que no se da en la castellana. En segundo lugar, podemos aducir pruebas textuales: una de las preguntas del apartado de fisiognomía figura en las ediciones italianas y también en la traducción castellana, pero no aparece en la traducción catalana ${ }^{148}$.

Lo más probable es que Pedro de Ribas trabajara con alguna de las ediciones italianas del libro de Manfredi que se imprimieron en el siglo XVI antes de 1567, que son reimpresiones de la edición príncipe de 1474 y que hemos

146 Edición citada por PÉrez PAStor (1891-1907), vol. 1, p. 317, § 595. Según PALAu DulCET (1948-1977), vol. 7, p. 553, ésta y la anterior serían, en realidad, distintos ejemplares de una misma edición.

147 Contiene la licencia real, firmada por Alfonso de Vallejo en Madrid el 7 de agosto de 1598, una lista de erratas de Juan Vázquez del Mármol, la «epístola» de Antonio de Furno a Fernando de Aragón, el «proemio» de Pedro de Ribas y el «compendio y sumario». La fecha de la licencia de impresión permite conjeturar que esta edición constituye una reimpresión de la edición consignada con el número 4.

148 «Perché i capilli rescaldano il capo essendo di sua natura fredi e sicci e similmente tosto se accendeno. El capillo rescalda il capo accidentalmente, in quanto reverbera e retiene il caldo naturale del capo stretto e unito, come fa le veste che sonno atorno il corpo. Tosto se accendeno e se rescaldano perché sonno de substantia sottile» (II, 1, 31, según TROMBETTI BUDRIESI, Foresti y NADA PATRONE, 1988, p. 186). «Porqué los cabellos calientan la cabeça siendo de su naturaleza fríos y secos, y semejantemente presto se encienden. El cabello calienta la cabeça accidentalmente en quanto reverbera y detiene el calor natural de la cabeça apretado y unido, como hazen las vestiduras que están alrededor del cuerpo. Presto se encienden y calientan porque son de sustancia delgada». Obtenemos el texto castellano de la edición de Zaragoza de 1567, f. 101. 
clasificado en el primer grupo. Ahora bien, se dan tan notables diferencias entre el texto de estas ediciones italianas y el de la traducción castellana que parece evidente que Pedro de Ribas manipuló el original italiano que tenía sobre la mesa. Veamos en qué consisten estas diferencias.

La primera y más notable radica en la propia autoría del texto. En efecto, en todas las ediciones italianas consta el nombre de Girolamo Manfredi en el proemio latino, mientras que en la traducción castellana la obra se presenta como anónima. Quizás la edición italiana manejada por Pedro de Ribas había perdido el prólogo latino y, por lo tanto, la mención de la autoría de la obra. Pero Antonio de Furno declara en la epístola que el libro italiano era «buscado y desseado de muchos», lo que nos permite deducir que se trataba de una obra muy conocida. Y si ello era así, también lo debía ser su autor, puesto que su nombre figuraba siempre al principio del texto. Por esta razón, nos inclinamos por pensar que Pedro de Ribas ocultó deliberadamente el nombre de Manfredi por el motivo que veremos enseguida.

Otra diferencia significativa entre las ediciones italianas y la traducción castellana radica en la tabla o sumario que distribuye el texto italiano en dos libros y diversos capítulos ( 7 y 13, respectivamente), y en la cual se explicitan todas las preguntas que contiene cada uno de los capítulos que siguen. A diferencia de las ediciones italianas del siglo $\mathrm{XV}$, en la traducción castellana no existe tabla alguna y el texto de Manfredi se desarrolla sin divisiones de ningún tipo, como ocurre también en las ediciones italianas del bloque $\mathrm{A}$. Si comparamos el número de preguntas que contiene la primera edición italiana del Liber de homine (Bolonia, 1474) ${ }^{149}$ con las de la traducción castellana de Pedro de Ribas, observamos un cómputo distinto:

\begin{tabular}{|l|c|c|}
\cline { 2 - 3 } \multicolumn{1}{c|}{} & Bolonia, 1474 & Zaragoza, 1567 \\
\hline LIBRO PRIMERO & preguntas & preguntas \\
\hline Capítulo 1 & 70 & $\mathbf{6 9}$ \\
\hline Capítulo 2 & 56 & 56 \\
\hline Capítulo 3 & 12 & 12 \\
\hline Capítulo 4 & 25 & 25 \\
\hline Capítulo 5 & 94 & $\mathbf{6 4}$ \\
\hline Capítulo 6 & 48 & $\mathbf{4 2}$ \\
\hline Capítulo 7 & 23 & $\mathbf{1 1}$ \\
\hline
\end{tabular}

149 Este cómputo es válido para todas las ediciones italianas del bloque A. 


\begin{tabular}{|l|c|c|}
\hline LIBRO SEGUNDO & preguntas & preguntas \\
\hline Capítulo 1 & 36 & $\mathbf{2 9}$ \\
\hline Capítulo 2 & 9 & 9 \\
\hline Capítulo 3 & 54 & $\mathbf{5 3}$ \\
\hline Capítulo 4 & 17 & 17 \\
\hline Capítulo 5 & 12 & $\mathbf{9}$ \\
\hline Capítulo 6 & 14 & 14 \\
\hline Capítulo 7 & 23 & 23 \\
\hline Capítulo 8 & 6 & 6 \\
\hline Capítulo 9 & 12 & 12 \\
\hline Capítulo 10 & 35 & $\mathbf{2 5}$ \\
\hline Capítulo 11 & 7 & 7 \\
\hline Capítulo 12 & 11 & $\mathbf{1 0}$ \\
\hline Capítulo 13 & 4 & $\mathbf{1}$ \\
\hline TOTAL & 568 & $\mathbf{4 9 6}$ \\
\hline
\end{tabular}

En la traducción castellana se han eliminado, pues, 72 preguntas respecto al original de Manfredi. Veámoslo con más detalle. La supresión del capítulo 1 del libro primero no tiene importancia para nuestro análisis, puesto que se trata de dos preguntas breves que se han fundido en una sola. Las seis preguntas suprimidas del capítulo 6 tratan del aire y de las ciudades septentrionales. Las doce preguntas discontínuas eliminadas del capítulo 7 tratan de movimientos del ánimo negativos, como el miedo y la ira —una de ellas mezcla la ira con la vergüenza y otra habla de la ansiedad. Las eliminaciones más sustanciales del primer libro son las del capítulo 5, que tienen un sentido muy concreto: se han suprimido catorce preguntas seguidas (de la 57 a la 70) que tratan del coito, luego siete y después ocho referidas al mismo tema. ${ }^{150}$ De las 34 preguntas referidas al coito que contiene el original italiano, han quedado sólo cinco en la traducción castellana.

Por lo que respecta al segundo libro, el tratado de fisiognomía, se han eliminado siete preguntas discontínuas del capítulo 1, también con claras conno-

150 Se han eliminado las preguntas de la 72 a la 78 , la 82 , la 84 y la 85 y de la 87 a la 91 . Anteriormente, se ha eliminado la pregunta 31 , pero por un error de salto de lectura del traductor. 
taciones sexuales ${ }^{151}$. Del capítulo 3 se ha suprimido una sola pregunta, que habla de los «etíopes» (hombres de raza negra). Se han obviado las tres últimas preguntas del capítulo 5, sobre la oreja, y diez preguntas del capítulo 10, una de las cuales una vez más referida al coito. Se han eliminado una pregunta sobre el estómago del capítulo 12 y las tres primeras preguntas del capítulo 13, que tratan de los órganos sexuales masculinos.

Podemos concluir, por tanto, que de un total de 72 preguntas eliminadas, 40 tienen relación con la sexualidad y 32 afectan a temas diversos. Las supresiones que Pedro de Ribas efectuó sobre el original italiano que tradujo obedecían a razones ideológicas concretas, que le llevaron a expurgar del Liber de homine aquellos fragmentos que el vicario zaragozano sabía que no se adecuaban a los ideales de la Contrarreforma y a suprimir el nombre de su autor para evitar cualquier posible problema con la censura' ${ }^{152}$. Tengamos en cuenta que el primer Index Librorum Prohibitorum fue publicado por el papa Pablo IV en 1559 y que se prohibieron libros de medicina, fisionomía, magia, astrología, etc., por lo que no ha de sorprender que el nombre de Manfredi, un médico y astrólogo famoso en Italia, fuera obviado por el traductor aragonés ${ }^{153}$.

A diferencia de Juan de Jarava, que en sus Problemas o preguntas problemáticas (1544) justificó su intervención en el texto, Pedro de Ribas en ningún momento declaró de forma explícita que manipulaba el texto que traducía. En cualquier caso, su proceder era perfectamente coherente con el desarrollo del género de los problemas. En su condición de eclesiástico, Pedro de Ribas ejerció la autocensura a conciencia, y lo máximo que se permitió fue manifestar que la temática del libro que traducía no atañía a su profesión, sometiéndose humildemente a la corrección y enmienda pertinentes si «lo que se ha traduzido no estuviere con aquel cumplimiento que se debe» (véase el Apéndice I). La primera reimpresión del Libro llamado el Porqué (Madrid, 1581) incluía ya una autorización del doctor Céspedes, médico de cámara de

151 Tres de ellas tratan del coito, otra se refiere a los «miembros pudientes», otra a los hombres castrados, otra a la barba masculina y otra a la ausencia de barba en las mujeres.

152 Véase al respecto PARdo TOMÁs, J. (1991), Ciencia y censura: la Inquisición Española y los libros científicos en los siglos XVI y XVII, Madrid, CSIC. Recordemos que en las ediciones italianas del Liber de homine realizadas a partir de 1588 se efectúan manipulaciones semejantes.

153 Aunque el nombre de Manfredi no aparezca en el índice de 1559 (http://www.aloha.net/ $\sim$ mikesch/ILP-1559.htm\#M) ni se cita en PARDO TOMÁs (1991), creemos que no se invalida nuestra hipótesis. 
Felipe $\mathrm{II}^{154}$, en la que se acredita la idoneidad científica y moral de las enseñanzas contenidas en el texto que se imprime (véase el apéndice II). Tenemos aquí un ejemplo poco habitual de ejercicio de la censura, puesto que ésta acostumbraba a estar en manos de teólogos que no podían juzgar fácilmente los libros científicos por falta de conocimientos ${ }^{155}$.

\section{EL ÉXITO POSTERIOR DE LA LITERATURA DE PROBLEMAS EN EL ÁMBITO IBÉRICO}

Las numerosas colecciones de problemas escritas originalmente en castellano, con sus reiteradas reimpresiones, que hemos visto en la primera parte de este trabajo, y las cinco ediciones del Libro llamado el Porqué de Manfredi publicadas en tan sólo treinta y un años, constituyen muestras más que evidentes del éxito de la literatura de problemas en la Castilla del siglo XVI. Eran obras destinadas a la divulgación científica que tenían un público diverso y constante, y que, por lo tanto, proporcionaban ganancias considerables a los impresores y editores, que no dudaban en invertir en una nueva edición cuando se agotaba la anterior.

Otras colecciones, que se escribieron e imprimieron hasta el siglo XIX, constituyen pruebas elocuentes de la vitalidad continuada del género de los problemas tanto en la Corona de Castilla como en la de Aragón. Sin pretender agotar el tema y como epílogo a todo lo dicho, recogemos a continuación seis obras escritas en prosa y que, significativamente, tratan de temáticas muy diversas.

El porqué de todas las cosas, del dominico aragonés Andrés Ferrer de Valdecebro, es una colección de problemas publicada en Madrid en 1668 y reimpresa por última vez en $1814^{156}$. Con un esquema y un contenido seme-

154 Este doctor Céspedes, que al parecer no publicó obra ninguna, formaba parte de los médicos de cámara de Felipe II, según consta en algunos documentos cortesanos en los que se transcriben consultas sobre la salud del rey. No se recoge en JiMÉNEZ MuÑOZ, J.M. (1977), Médicos y cirujanos en 'Quitaciones de Corte' (1435-1715), Valladolid, Universidad de Valladolid. Agradecemos a José Pardo Tomás (CSIC, Barcelona) y a Mar Rey Bueno (Universidad de Valladolid) sus informaciones al respecto.

155 PARdo TOMÁs (1991), pp. 273-274, expone el caso de la petición infructuosa de un calificador en la que solicitaba que también médicos y cirujanos pudieran examinar como censores los libros científicos.

156 Palau Dulcet (1948-1977), vol. 5, p. 370: «Este libro es una especie de enciclopedia de conocimientos populares expuestos en forma un tanto candorosa. Luego se reimprimió bajo el nombre de Andrés Ferrer de Brocaldino». Palau cita siete ediciones: Madrid, 1668; Madrid, 
jante a los que hemos visto en las colecciones de problemas del siglo XVI, Andrés Ferrer de Valdecebro inicia su Tratado de Philosophía ${ }^{157}$ con un prólogo redactado en un lenguaje algo obtuso en el que pone de manifiesto la relación de su obra con la tradición de los problemas pseudo-aristotélicos: ${ }^{158}$

El Príncipe y Maestro de la Philosophía Aristóteles escrivió unos Problemas, que aumentaron a Aberroes, Aphrodisco y Zimara, para beneficio común de los que la professan [sic]. Yo las prosigo y añado en nuestro idioma castellano, con todo lo que mi cortedad ha podido dar de sí. Las reparto en dos Libros: el primero, es Philosohía natural; el segundo, Moral. La una aviva el ingenio, la otra el espíritu. (p. 3)

La inclusión de Marcantonio Zimara (1470-ca. 1532) ${ }^{159}$ entre las autoridades citadas en este párrafo permite deducir que para Ferrer de Valdecebro las colecciones italianas formaban parte de la tradición clásica. Más aún: él mismo sitúa a su propia obra en la tradición de los libros de problemas que se ha ido construyendo poco a poco:

Algunos han traducido estos Problemas, ya en italiano, ya en castellano. Ya lo he visto, y no he visto qué sea lo que escriven, como lo que escrivo. Mucho he traducido y mucho añado, y pienso que añado más que he traducido. No lo señalo porque ello mismo dirá a voces de que es mío. (pp. 3-4)

Las Definiciones y elementos de todas las ciencias: obra util para la educación de la juventud - traducción del original francés de Johann Heinrich Samuel Formey Abrégé de toutes les sciences à l'usage des enfans (1757), realizada por Miguel Copín y publicada por primera vez en Madrid en $1775^{160}$ — constituyen una obra de carácter pedagógico, como se desprende

1762; tres ediciones realizadas en Barcelona (1764, ca. 1775 y otra sin fecha pero del s. XVIII), otra en Madrid a finales del siglo XVIII y una en León en 1814.

157 Así lo denomina en la p. 4. Hemos utilizado el ejemplar que se conserva en la Biblioteca de la Universitat de Barcelona, B. 56-7-36. Es un ejemplar de la edición de Barcelona impresa por Pau Campins en 1764, en la que se atribuye la obra a «Andrés Ferrer de Brocaldino».

$158 \mathrm{Su}$ relación con los problemas pseudo-aristotélicos se hace evidente también si observamos el contenido de los 35 capítulos del libro primero: los hay dedicados al hombre, a la mujer, a la generación, a los ojos, la nariz, las orejas, la voz, el pecho, los brazos, a los órganos internos como el estómago, el hígado, etc. (pp. 130-131).

159 Sobre este comentarista paduano de Aristóteles y de Averroes, autor de unos Problemata escritos entre 1509 y 1514, véase LAWN (1963), pp. 129-130.

160 Palau Dulcet (1948-1977), vol. 4, p. 339, apunta que «esta obra obtuvo un gran éxito comercial, como lo prueban las muchas reimpresiones». 
del título y lo deja bien claro el prólogo ${ }^{161}$. Por ello ofrecen un conjunto muy ordenado de 78 breves capítulos que preguntan y responden a todas las materias que un joven instruido debía conocer ${ }^{162}$.

El porqué de la música ${ }^{163}$ fue publicado en 1672 en Alcalá de Henares por Andrés Lorente, comisario del Santo Oficio en Toledo ${ }^{164}$. Es una obra con numerosos pentagramas para facilitar la comprensión del texto que, aunque no está estructurada en su totalidad en forma de preguntas directas y respuestas, sí que contiene gran número de ellas ${ }^{165}$.

Casi un siglo más tarde, se publica en Figueres El porqué de todas las ceremonias de la iglesia y sus misterios (1758) ${ }^{166}$, cuyo autor, Antonio Llobera y $\mathrm{Abio}^{167}$, divide la obra en cuatro tratados articulados en forma de preguntas

161 Miguel Copín explica que la obra va dirigida a la educación de la juventud, no de la infancia, y apunta que el recopilador en francés es Mr. Formey (p. VI). Utilizamos el ejemplar de la Biblioteca de la Universitat de Barcelona, XIX-352, correspondiente a la edición impresa en Barcelona por Juan Francisco Piferrer entre 1775 y 1788.

162 El índice final expone los temas tratados: la religión, la teología, las ciencias y las artes, la física, la lógica, la gramática, la poesía, los diversos fenómenos atmosféricos, la medicina, la cirugía, la botánica, la imprenta, la música, el baile, el comercio, la óptica, la cosmografía, la geografía, la historia, etc. La obra finaliza con unos capítulos dedicados a las casas imperiales y reales.

163 El título completo es El porqué de la música, en que se contiene los quatro artes de ella, canto llano, canto de órgano, contrapunto y composición y en cada uno de ellos nuevas reglas, razón abreviada, en útiles preceptos, aún en las cosas más difíciles, tocantes a la harmonia de la música, numerosos exemplos. Hemos visto el ejemplar conservado en la Biblioteca de la Universitat de Barcelona, 0700 C-186/2/7.

164 En el título de la obra consta que Andrés Lorente, natural de Anchuelo, era graduado en artes por la Universidad de Alcalá, comisario del Santo Oficio en Toledo y organista y racionero de la Iglesia Magistral de San Justo y Pastor de Alcalá de Henares.

165 Por ejemplo, en el libro tercero, dedicado al arte del contrapunto, se pregunta: «¿Por qué se llaman el unisonus, la quinta y sus compuestas, especies perfectas?» (p. 236). Y en el libro 4 leemos: «¿Sostenido, qué sea?», «ßBemol, qué sea?», «¿Fantasía, qué sea?», etc. (pp. 506-507).

166 El porqué de todas las ceremonias de la iglesia y sus misterios. Cartilla de prelados y sacerdotes que enseña las ordenanzas eclesiásticas que deben saber todos los ministros de Dios, escrito y compuesto por don Antonio Lobera y Abio... en forma de diálogo symbólico entre un vicario instruido y un estudiante curioso. Véase PALAU DULCET (1948-1977), § 139406. Consultamos el ejemplar de la Biblioteca de la Universitat de Barcelona, 0703 B66/6/17.

167 Antonio Llobera y Abio era presbítero, beneficiado de la parroquia de San Gil Abad de Zaragoza y capellán mayor del regimiento real de infantería de la reina, según consta en el título de la obra. 
y respuestas, formuladas las primeras por un estudiante llamado «Curioso» y respondidas por el «Vicario», que es el personaje que posee el saber. La obra debió alcanzar un éxito casi inmediato, pues nos consta una reimpresión en 1769168 .

La publicación en Figueres de El porqué de todas las ceremonias de la iglesia, junto con las reimpresiones barcelonesas de la obra de Ferrer de Valdecebro y de la traducción de Miguel Copin de la obra de Formey, pone de manifiesto que el género de los problemas gozaba de prestigio también en los territorios de la antigua Corona de Aragón, donde inició sus andaduras en 1499 con la traducción al catalán de la obra de Girolamo Manfredi, como hemos visto ${ }^{169}$. Podemos citar algunos testimonios más que prueban la vigencia del género en esas tierras. En primer lugar, la publicación de la anónima Luz de la verdad: preguntas y respuestas a favor de Cataluña y sus hijos ${ }^{170}$, que apareció en 1641, en el contexto de la guerra de Separación, popularmente conocida como dels Segadors. Se trata de un diálogo entre diversos personajes que se preguntan y responden, sin el emblemático «por qué» al inicio de cada cuestión, aunque el título de la obra la vincula directamente con el género ${ }^{171}$. El segundo testimonio es Lo perquè de Barcelona y memòrias de ses antiguedats $^{172}$, obra escrita en catalán hacia $1734-1748$ por el erudito ilustra-

168 El ejemplar que hemos visto es de 1769, según consta en la licencia, datada en Girona, a 7 de marzo de 1769. Se explicita que la primera edición fue efectuada en 1758 (p. 5).

169 Si más allá de 1499 no existen ejemplos en catalán del género en cuestión, ello es debido a las circunstancias políticas y culturales que afectaron a la historia de la lengua catalana y que no pretendemos abordar aquí. Véase CIFUENTES, Ll. (2002), La ciència en català a l'Edat Mitjana i el Renaixement, Barcelona, Universitat de Barcelona-Palma, Universitat de les Illes Balears, pp. 77-79.

170 El título completo es Luz de la verdad, preguntas y respuestas a favor de Cataluña y sus hijos, originadas de una disputa avida entre cinco soldados de a cavallo de las tropas de España dispuestas en la forma siguiente por uno de los mesmos propugnantes. No consta ni el nombre del impresor ni el lugar de impresión. Véase PALAU DULCET (1948-1977), § 144294, nota, que añade: «Algunos afirman que su autor es Fr. Bernardo de Ribera»; SIMÓN PALMER, Ma.C. (1980-1982), Bibliografía de Cataluña: notas para su realización, 2 vols., Madrid, CSIC, § 529. Ejemplar en la Biblioteca de la Universitat de Barcelona, B 73/4/32.

171 Quizás no sea una constatación menor la coincidencia del título de esta obra, Luz de la verdad, con el de algunas ediciones italianas tardías de la obra de Manfredi, concretamente las de 1668 y 1678, Il novo lume dell'arte (véase la nota 122), seguramente fruto de los contactos culturales existentes entre las penínsulas Ibérica e Itálica, como hemos apuntado al principio de este trabajo.

172 PARÉS, R.D. (1929), «Un manucrit català: Lo perquè de Barcelona de Pere Serra y Postius. Memòria llegida en la Real Academia de Buenas Letras de Barcelona, 13 de gener de 1925», Memorias de la Real Academia de Buenas Letras de Barcelona, IX/4, 126 pp. 
do Pere Serra i Postius (1671-1748) en forma de diálogo entre el autor (Pere) y el hijo de un austracista emigrado (don Ramon). Lo perquè de Barcelona, que contiene a veces el «per què» emblemático, ${ }^{173}$ constituye una viva descripción de la ciudad de la época, de sus transformaciones urbanas y de sus leyendas locales que mantiene vivo también en el título el género literario de los problemas ${ }^{174}$.

173 Por ejemplo: «Però la Plaça del Regomí, la Plaça de Basea y de Marcús, per què axí las anomenan?» (PARÉS, 1929, p. 45), etc.

174 Este trabajo se inscribe en el marco de los proyectos de investigación financiados por el MEC Medicina y literatura en la Baja Edad Media y el Renacimiento hispánicos: textos prácticos, didácticos y literarios en lengua vernácula (HUM2004-05176/FILO, IP Lluís Cifuentes, Univ. de Barcelona, con Antònia Carré), y Corpus digital de textos catalanes medievales/Llull (HUM2005-07480-C03-01, IP Lola Badia, UB, con Ll. Cifuentes); y en el grupo de investigación consolidado financiado por el DURSI de la Generalitat de Catalunya Grup de cultura i literatura a la Baixa Edat Mitjana (SGR2005-00346, IP Lola Badia, UB, con A. Carré y Ll. Cifuentes). Forma parte de las líneas de investigación de cada uno de sus autores, sobre las relaciones entre medicina y literatura en la cultura catalana medieval y sobre la difusión vernácula de la ciencia y de la técnica en el marco ibérico medieval, respectivamente, amparada esta última por el Programa Ramón y Cajal del MEC. Deseamos manifestar nuestro agradecimiento a todas aquellas personas e instituciones que nos han ayudado en algún momento de la investigación. En particular, a Jon Arrizabalaga (Institución Milà i Fontanals, CSIC), Lola Badia (Universitat de Barcelona), Carmen Caballero (Universidad de Granada), Miriam Cabré (Universitat de Girona), Rosanna Cantavella (Universitat de València), José Pardo Tomás (CSIC, Barcelona), Mar Rey Bueno (Universidad de Valladolid), Alessandra Veronese (Università di Pisa) e Ilaria Zamuner; así como a las bibliotecas e instituciones cuyos fondos e instalaciones hemos utilizado, en particular al Departamento de Historia de la Ciencia de la Institución Milà i Fontanals del CSIC en Barcelona, al Institut Botànic de Barcelona y al monasterio de Poblet. 


\section{APÉNDICE I \\ EDICIÓN DE ZARAGOZA DE 1567175}

\section{[EPÍSTOLA DE ANTONIO DE FURNO] ${ }^{176}$}

Al excellentíssimo y reverendíssimo señor, Don Hernando de Aragón, arçobispo de Çaragoça, visorey de Aragón.

Vemos, excellentíssimo y reverendíssimo señor, cada día tan grandíssimas differencias en las naturalezas y inclinaciones de los hombres que muy pocos se hallan que en todas sus cosas concierten, que como pocas vezes se hallan dos que en effigie y lineamentos del cuerpo sean semejantes, assí también pocas vezes se hallan dos en una voluntad conformes, de manera que si en una cosa se concertaren, en otras muchas tendrán diversos pareceres. Uno ay que en qualquier obra que se le proponga, por muy acostumbrada y fácil que sea, luego halla difficultades, y con sus argumentos haze que lo que es muy possible parezca impossible y haze desconfiar del buen fin. Otro avrá de tal condición que ninguna cosa tendrá por impossible y quando más diffícil parece lo que se le propone y en que menos se confíe que pueda llevarse al cabo, tanto más fácil cree y dize que es; ni por argumento que en contrario se trayga se le turba, antes bien, con la agudeza de su delicado ingenio, lo que por todos era tenido por difficultosíssimo y que no se descubría camino como pudiesse effectuarse, él lo haze y acaba con mucha facilidad. Estos tales ordinariamente son muy gratos a príncipes y grandes señores y de quien el vulgo se admira y cree que son más que hombres, viendo por medio dellos, con su industria, effectuarse obra a su opinión impossible, y si el vulgo entensiesse la sutileza del ingenio humano, moderaríase algo su admiración.

Por esto he procurado, con la diligencia que he podido, de aver este libro, buscado y desseado de muchos, pareciéndome que con él cumpliría con los ingenios subidos y delicados y con los que no lo son tanto: a los unos dando razón de lo que dudavan y a los otros mostrándoles que en lo que llevan muy entre las manos ay difficultades, declarándoles también las causas. Teniendo algunos noticia deste libro, pidíanmelo con grande instancia; viendólo después en lengua italiana, y no la entendiendo, recibían pesadumbre y molestia. Importunáronme algunos que lo hiziesse traduzir en lengua castellana para que todos puedan gozar dél, pues en todos - como dize Aristótiles - es cosa natural el desseo de saber $^{177}$. Con esto di cargo a quien de italiano lo hiziesse español.

Viendo, pues, que libro de ingenio no devía offrecerse sino a quien tan bueno le tiene como Vuestra Excellencia, determiné de dirigírselo, pareciéndome que no solamente no

175 Las transcripciones han sido realizadas a partir del ejemplar de la edición de 1567 conservado en Madrid, BN, R 82299. Introducimos puntuación y acentuación modernas, y regularizamos el uso de las mayúsculas y de $\mathrm{i} / \mathrm{j}$ y u/v. Los dos primeros títulos son nuestros.

176 Ocupa los ff. II- IIIV.

177 La cita corresponde al incipit del Omnes homines, procedente del primer libro de la Metafísica de Aristóteles. Del Furno se muestra familiarizado, pues, con la larga tradición de la literatura de problemas. 
perdería en España el crédito y autoridad que tiene en Italia, mas antes que en gran manera se le augmentaría viendo todos ser Vuestra Excellencia su patrón y amparo, cuya prudencia y valor en todo el mundo se conoce, lo qual entendiendo la Magestad del rey Don Phelippe, nuestro señor, le ha encomendado el gobierno de todo este reyno. Bien conozco ser el servicio muy corto, pero mi desseo es grande, al qual en alguna manera satisfaré, manifestando con esto mi affición, que ha sido siempre y es muy inclinada al servicio de Vuestra Excellencia, cuya excellentíssima y reverendíssima persona Dios guarde y prospere muchos años, como este reyno dessea y ha menester.

De Vuestra Excellencia muy cierto servidor, que sus reverendíssimas manos y pies besa, Antonio de Furno.

\section{[NOTA DE ANTONIO DE FURNO AL LECTOR] $]^{178}$}

Antonio de Furno, mercader de libros vezino de Çaragoça, al lector:

Como mi fin y desseo no sea otro sino aprovechar y servir con mi arte a los curiosos y desseosos de entender las cosas de naturaleza y a los no curiosos animar para que a ello se apliquen, no perdono a mi trabajo. Viniendo, pues, a mis manos un libro italiano intitulado El porqué, provechosíssimo para la conservación de la salud y conocimiento de phisionomía y virtud de las yerbas, pareciéndome en su estilo ser de persona curiosa y docta en aquellas sciencias, y que estando en lengua differente de la nuestra no sería conocido, di cargo a quien, con fidelidad y diligencia, lo traduxesse y pusiesse en orden ${ }^{179}$ para que todos pudiessen participar de lo que en él ay, pues mi zelo no es otro que el dicho. Suplico al lector lo reciba con affición y mire al fin que tengo de servirle, porque será para darme ánimo a que siempre vele y procure de emplearme en cosas de más calidad para utilidad y provecho de todos.

\section{PROHEMIO DE PEDRO DE RIBAS 180}

Prohemio de Pedro de Ribas, vicario de San Nicolás, intérprete desta obra, al lector.

Bien entiendo parecerá al vulgo ser fuera de propósito, por no tocar a mi professión, el aver emprendido la traductión deste libro, pero como muchas vezes las personas importunadas por amigos les sea forçado doblarse a lo que por ventura sus fuerças pequeñas no podrían recabar, no obstante esso, por no parecer del todo ingrato a quien de mi tenía alguna opinión, en que para ello hallava un poco de talento, el qual, si algo es, puedo dezir ser casi nada, determiné aderecer a sus rogarías, aunque con temor. Diome, a más desto, ánimo a ello por entender, de personas de la misma erudición del auctor, sería provechoso a la gente plebeya y curioso para espíritus gentiles y desseosos de saber cu-

178 En el f. IV.

179 Podríamos ver aquí una referencia indirecta a la expurgación a que fue sometida la obra de Manfredi.

180 En los ff. V-VI. 


\section{ANTÒNIA CARRÉ y LLUÍS CIFUENTES}

riosidades. Y como Antonio de Furno, a cuya costa se ha impresso, tenga siempre cuydado en servir y aprovechar con grandíssimo desseo a la república, me sea amigo y familiar, me movió para ello. Y assí, si la traductión de dicha obra no estuviere tan limada ni con la destreza que ella merece, atribuyrle han no solamente que estando ella en lengua la más difficultosa de reduzir a la nuestra española de quantas en Italia he visto, más aún a mi ingenio, el qual no es sotil ni más limado que otro.

Acostumbran, los que traduzen, buscar libros que sean provechosos para la sanidad de los hombres, y si alguno muchos días ha se ha buelto de idioma estrangero en nuestro vulgar $^{181}$ es este, porque allende que en él ay remedios muy útiles para la conservación de la vida humana, tiene también secretos y propriedades de yerbas para nuestros mantenimientos necessarias, que recrearán muy mucho al que con diligencia las leyere, lo qual por experiencia el curioso lector podrá ver. Bien quisiera escusarme deste trabajo, porque los que tenemos cuenta de apascentar ovejas nos auríamos de emplear en buscalles pastos deleytosos y apazibles, mas - como dize el proverbio- successivis horis se ha de exercitar el hombre en cosas de plazer sin perjuyzio de tercera persona, y holgarse honestamente offreciéndose tal ocasión, pues de tal exercicio no poco provecho resulta a todos los amadores y desseosos de saber, pues nadie no ay en esta vida que dello natural apetito no tenga; ${ }^{182}$ y los que en alguna cosa honesta y apazible no ponen la mano, aman a mi ver la ociosidad, la qual es fundamento y origen de muchos males, los quales cotidianamente vemos acontecer. Y así, por no ser reprehendido de vicio tan abominable, me ha parecido, pues cosa es loable, disponer mi ingenio en negocio tan bueno y no dexar passar el tiempo - cosa la más preciada, según doctrina de todos los philósophos, que en esta vida ay- en vano y sin sacar dél algún emolumento.

Por lo qual, si lo que se ha traduzido no estuviere con aquel cumplimiento que se debe, con la humildad a mí possible me subjeto a la correctión y emienda de los que esta arte mucho mejor que yo la entienden, pues como varón que agora principio, he emprendido semejante obra para mí, por cierto, mucho mayor de lo que mis fuerças bastavan. No uso de más abundancia de palabras por no parecer a Ulisses, capitán griego, el qual, contendiendo con Ajax Thelamonio sobre las armas de Achiles a quien se avían de dar, con su torrente de bien hablar y abundancia de plática pretendió averlas él de recebir, teniendo en muy poco a su contrario, no siendo en fuerças y ánimo a él inferior, contentándome con la brevedad que a todos aplaze y a nadie es molesta, y por el contrario la superfluydad y abundancia de palabras daña más que aprovecha.

${ }^{181}$ Puesto que no se conoce ninguna traducción castellana o aragonesa anterior a la suya, Pedro de Ribas podría referirse a la traducción catalana impresa en Barcelona por Pere Posa en 1499. Con la expresión «nuestro vulgar» aludiría simplemente a la que fue principal lengua de cultura y de gobierno en la Corona de Aragón, que no era extraña a las élites del propio reino estricto de Aragón.

182 Otra vez, el incipit del Omnes homines. 


\title{
COMPENDIO Y SUMARIO DE TODO LO QUE CONTIENE EL PRESENTE LIBRO ${ }^{183}$
}

Primeramente, trata de cosas pertenecientes a la salud de nuestros cuerpos y phisonomía.

Segundariamente, trata de la virtud de las yerbas.

Tercera y últimadamente, un sumario de todos los mantenimientos y yerbas necessarias para la vida humana.

\author{
APÉNDICE II \\ REIMPRESIÓN DE MADRID DE $1581^{184}$
}

\section{TASSA 185}

Yo, Pedro Çapata del Mármol, escrivano del Consejo de Su Magestad, doy fee que los señores del Consejo de Su Magestad tasaron un libro que con su licencia hizo imprimir Guillermo Druy, intitulado El porqué, a cinco blancas cada pliego en papel. Y a este precio y no más le dieron licencia para le poder vender, con que antes que le venda imprima esta tasa al principio del dicho libro. En fe de lo qual, para que dello conste, di la presente firmada de mi nombre.

Fecha en Madrid, a diez y nueve de abril de mil y quinientos y ochenta y un años.

Pedro Çapata del Mármol.

\section{LICENCIA $^{186}$}

Don Philippe, por la gracia de Dios, rey de Castilla, de León, de Aragón, de las Dos Sicilias, de Hierusalem, de Navarra, de Granada, de Toledo, de Valencia, de Galizia, de Mallorcas, de Sevilla, de Cerdeña, de Córdova, de Córcega, de Murcia, de Jaén, de los Algarves, de Algezira, de Gibraltar, conde de Flandes y de Tyrol, etc. Por quanto por parte de vos, Guillermo Druy, impressor de libros residente en nuestra corte, nos ha sido fecha relación que vos teníades un libro llamado El porqué, que tratava de la conservación de la vida humana y regimiento del cuerpo, el qual era muy útil e provechoso, e nos suplicastes os mandásemos dar licencia para le poder imprimir, o como la nuestra merced fuesse; lo qual, visto por los del nuestro Consejo, y como por su mandado se hizieron las

183 En el f. VIv.

184 Transcribimos los textos que siguen a partir del ejemplar de la edición de 1581 conservado en Madrid, Real Academia Española, sign. 11-XI-41. Obviamos las erratas, así como el Proemio de Pedro de Ribas y el Compendio y sumario, éstos ya transcritos en el Apéndice I. Los tres últimos títulos son nuestros.

185 En el f. 2.

186 En los ff. 3v-4. 


\section{ANTÒNIA CARRÉ y LLUÍS CIFUENTES}

diligencias que la pragmática por Nos nuevamente fecha sobre la impressión de los libros dispone, fue acordado que devíamos mandar dar esta nuestra carta para vos en la dicha razón, e Nos tuvímoslo por bien. E por la presente, os damos licencia y facultad para que, por esta vez, podáys imprimir el dicho libro que de suso se haze mención, por el original que en el nuestro Consejo se vio que va rubricado y firmado al cabo de Pedro Çapata del Mármol, nuestro escrivano de cámara de los que en nuestro Consejo residen; y con que antes que le vendáys le traygáys al nuestro Consejo juntamente con el dicho original para que se corrija con él y se os tasse el precio que por cada volumen oviéredes de aver, so pena de caer e incurrir en las penas contendias en la dicha pragmática y leyes de nuestros reynos. De lo qual mandamos dar y dimos esta nuestra carta, sellada con nuestro sello y librada por los del nuestro Consejo.

Dada en la villa de Madrid, a 5 días del mes de junio de 1579 años.

Antonius, el licenciado. El licenciado Juan.

Espiscopus Fuenmayor. Thomás, el licenciado.

El licenciado Lope. El licenciado Ximénez.

Covarruvias. De Guzmán. Ortiz.

Yo, Pedro Çapata del Mármol, escrivano de cámara de su Cathólica Magestad, la fize escrevir por su mandato, con acuerdo de los de su Consejo.

\section{[AUTORIZACIÓN DEL DOCTOR CÉSPEDES] ${ }^{187}$}

Yo, el doctor Céspedes, médico de Su Magestad, vi este libro llamado El porqué e le leý partida por partida, e no hallé en él cosa que se ha de quitar ni enmendar, sino que está lleno de muy buena philosophía y ni ay palabra mal sonante contra nuestra religión. Y ansí, digo que merece se le dexe imprimir.

En Madrid, a dos de junio de .79., por mandado del Real Consejo.

El doctor Céspedes.

\section{[DEDICATORIA AL LICENCIADO RUYPÉREZ DE RIBERA] ${ }^{188}$}

Al muy illustre señor, el licenciado Ruypérez de Ribera, del Consejo de Su Magestad y su fiscal en sus Consejos de Hazienda y Contaduría mayor della.

Este Libro del Porqué me pareció dirigir a Vuestra Merced porque, demás de que contiene muchos avisos naturales por vía de preguntas, es justo y razonable que cada persona en su género cumpla con sus obligaciones, de las quales yo me siento tan cargado que determino ya que no pueda darles satisfación por entero. Que vea Vuestra Merced que, en la parte que puedo, las reconozo. Y porque las cosas que la voluntad ofrece no pueden tener nombre de pobres ni pequeñas, no mida Vuestra Merced este servicio tanto

187 En el f. 4v.

188 En el f. 5 rv. 
en lo que es quanto en lo que yo quiesiera que fuera. Cuya muy illustre persona nuestro Señor guarde, con el aumento que sus servidores desseamos.

Muy illustre señor, vesa a Vuestra Merced las manos su mayor servidor,

Gaspar de Ortega.

\section{[PRÓLOGO DE GASPAR DE ORTEGA AL LECTOR] ${ }^{189}$}

Gaspar de Ortega, librero, al curioso lector.

Entre las cosas más convenientes y necessarias para la conservación de nuestra vida humana me parece, discreto lector, la philosophía natural, la qual es de tanta excelencia que Aristóteles, príncipe della, se preció tanto de que el mundo le llamase philósopho, sabiendo otras sciencias como las supo. Y así, juntamente con él, ubo otros muchos doctíssimos varones, assí antiguos como modernos, que se preciaron deste nombre y escrivieron della muy copiosamente. Pero es en tantos libros y con tantas difficultades que se requiere mucho tiempo para aver la substancia dellos, por lo qual, no aviendo tiempo que baste para verlas ni leerlas todas, quiso el auctor deste libro sacar de todos ellos estos problemas y preguntas naturales, añadiendo en ellas algunas cosas, y poniendo otras suyas ${ }^{190}$; obra, cierto, digna de loor y que merece tan justamente ser admitida de todos, por ser tan provechosos para la salud y gusto de las gentes. Tradúxolos de lengua italiana, en que el auctor primero las escrivió, en la castellana Pedro de Ribas, natural de Çaragoça. Y porque la primera impressión que entonces se hizo se avía acabado, me determiné agora de tornarlos a sacar a luz, porque no se perdiesse la memoria de tantas y tan excelentes preguntas. Sólo he puesto de mi parte alguna diligencia para enmendar algunos lugares que por causa de la primera impressión no eran bien entendidos. Y deste trabajo no quiero más premio de que se entienda mi buen celo, que es ser de algun provecho a mi patria.

Fecha de recepción: 20 de mayo de 2005

Fecha de aceptación: 13 de enero de 2006

189 En el f. 6rv.

190 Como Antonio de Furno y Pedro de Ribas, el librero Gaspar de Ortega manifiesta conocer el funcionamiento de la literatura de problemas. 
